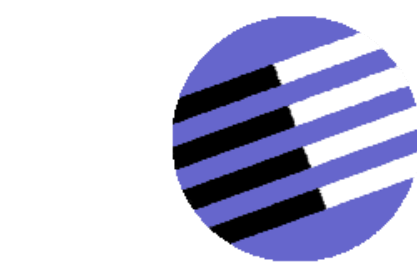

GOVERNANCE AND THE EFFICIENCY

OF ECONOMIC SYSTEMS

GESY

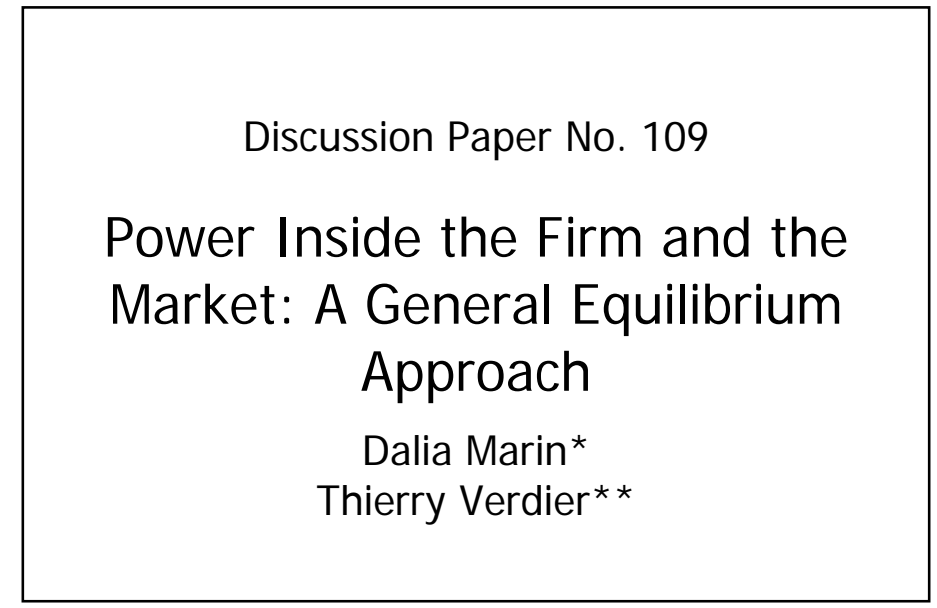

first version: December 2001

this version: March 2006

*Dalia Marin, Department of Economics, Ludwigstr. 28, 80539 Munich, phone: +49-89-2180-2446, fax: +49-89-21806227. dalia.marin@Irz.uni-muenchen.de

**Thierry Verdier, DELTA, Paris

Financial support from the Deutsche Forschungsgemeinschaft through SFB/TR 15 is gratefully acknowledged. 


\title{
Power Inside the Firm and the Market: A General Equilibrium Approach*
}

\author{
Dalia Marin, University of Munich ${ }^{\dagger}$ \\ Thierry Verdier, DELTA, Paris
}

First Version: December 2001

This Version: March 2006

JEL classification: F12, D23, L22, L1

Keywords: monopolistic competition, international trade, corporate reorganisation, flattening firm hierarchies

*This paper has been partly written when Dalia Marin visited Harvard University and NBER. We thank Philippe Aghion, Micael Castanheira, Elhanan Helpman, Thorsten Hens, John McLaren, Marc Melitz, Michael Raith, Oved Yosha and two anonymous referees for helpful comments and participants at seminars at Harvard University, Boston University, University of Pennsylvania, University of Zurich, University of Lausanne, Free University Berlin, Humboldt University Berlin, University of Munich, The World Bank, International Monetary Fund, NBER International Trade and Organizations Program Meeting, Cambridge, CEPR-SITE Euroconference on 'Incentives and Beyond: The Economics of Personnel and Organizations', Stockholm, European Research Workshop in International Trade (ERWIT), Munich, and at the Annual Congress of the Verein für Socialpolitik, Zurich.

${ }^{\dagger}$ Corresponding author: Department of Economics, Ludwigstr. 28, 80539 Munich, phone: +49-89-2180-2446, fax: +49-89-2180-6227, e-mail address: dalia.marin@lrz.uni-muenchen.de 


\begin{abstract}
Recent years have witnessed an enormous amount of reorganization of the corporate sector in the US and in Europe. This paper examines the role of market competition for this trend in corporate reorganization. We find that at intermediate levels of competition the $\mathrm{CEO}$ of the corporation decides to have less power inside the firm and to delegate control to lower levels of the firms' hierarchy. Thus, workers empowerment and the move to flatter firm organizations emerge as an equilibrium when competition is not too tough and not too weak. The model predicts merger waves or waves of outsourcing when countries become more integrated into the world economy as the corporate sector reorganizes in response to an increase in international competition.
\end{abstract}




\section{Introduction}

In the last two decades the corporate sector in the US and more recently in Europe has gone through an enormous amount of restructuring. More than half of all Fortune 500 firms have either been targets of takeovers or been involved in some other sort of corporate struggle that has led them to restructure their operations. At the same time, firms reorganized their activity by eliminating layers of middle management, by introducing more decentralized decision making inside the corporation and by empowering workers at lower levels of the firm hierarchy. These developments resulted in flatter hierarchies within corporations. ${ }^{1}$

What accounts for these changes in corporate organization? It is often argued that hierarchies are inflexible and inefficient. One of the reasons why hierarchies are bad is that decisions have to be approved by several people before they can pass. ${ }^{2}$ Another reason is that hierarchies might leave too little room for initiative to individual workers' leading to inefficient production. The lack of initiative of the firm's work force might have a particular strong negative impact on the firm's performance when it moves into new activity with less experience. The trend to workers empowerment is then a way to tackle these inefficiencies.

Instead of looking at the possible weaknesses in the internal control mechanisms of firms, we focus in this paper on changes in the economic environment that can explain why firms have shifted the mode of organization. Recent years have witnessed a surge in deregulation, both on the national as well as on the international level. The resulting increase in competitive pressure might have been the driving force behind the search for modes of organization which are "mean and lean". ${ }^{3}$ In this paper we develop a theory of organization in which the firm adapts its organization to changes in market conditions.

\footnotetext{
${ }^{1}$ For a description of recent trends in corporate organization see Holmstrom and Kaplan (2001). For the phenomenon of empowerment in organizations see Argyris (1998) and Mohrman, Galbraith, and Alwair (1998), for empirical evidence on the trend to flatter corporate hierarchies see Rajan and Wulf (2003).

${ }^{2}$ In their assessment of how different systems explore and innovate Sah and Stiglitz (1986) argue that hierarchies are particularly bad in times of change. For an evaluation of the comparative advantage of hierarchies and markets, see Holmstrom (2000), from the transaction cost perspective, see Williamson (1975), from the property rights perspective see Grossman and Hart (1986), Hart and Moore (1990).

${ }^{3}$ Holmstrom and Kaplan (2001) argue that the drivers of the changes in corporate governance in the 1980s and 1990s are economy wide trends in deregulation, globalization, and information
} 
In a recent paper Aghion and Tirole (1997) (henceforth AT) develop a theory of organization which is based on Max Weber's distinction between "rational" and "legal" authority. AT describe the allocation of formal authority within organizations and of the separation between "formal authority" and "real authority". A CEO of a corporation who has "formal" authority over a decision can reverse her subordinate's decision but will refrain from doing so if the subordinate is much better informed and if she can trust him. The subordinate then has "real", but no "formal", authority. Delegating formal decision power to the subordinate decentralization of decision making within the firm - comes with the benefit of increasing the subordinate's initiative but at the cost of the CEO's loss of control over the decision.

In this paper we are combining the AT model of firm organization with a Dixit and Stiglitz (henceforth DS) model of monopolistic competition to describe the interaction between the firm's mode of organization on the one hand and market competition on the other hand in a general equilibrium framework. The paper's contribution is in the following. First, the AT model describes the power dynamics within a single firm but neglects the market environment in which the firm operates. Thus, the firm's profits and the conflict of interest between the CEO and her division manager remain exogenous in the AT model. In this paper we endogenize the firms profits by the degree of market power firms hold in product markets for differentiated goods. Second, the DS model describes competition among firms with market power but neglects the dynamics inside the firm. We are opening the black box of the firm as an organization by modelling the power dynamics between different layers of management. The integration of the two models will allow us to examine how market competition affects the firm's organization on the one hand and how the firm's mode of organization feeds back to the market place on the other.

We develop a general equilibrium model with a monopolistic competitive sector with differentiated goods. Consumers have preferences over varieties. Production of the varieties in the monopolistic competitive sector is as in AT. A principal hires an agent to monitor projects and workers to produce. There are $m$ potential methods of production of which one maximizes profits and another one maximizes a private benefit for the agent.The principal and the agent gather information

technology. See also Bolton and Scharfstein (1998) for a survey of theories of organizational change based on weaknesses in the internal control mechanism of firms. 
which of the $m$ ways to run the firm maximizes profits and the private benefit of the agent, respectively. If both agents find out which are their preferred projects, the decision rights reside in the agent with formal authority. If only one of the agents learns which her preferred project is, the uninformed agent always rubber-stamps this project. In this case, the informed party has real authority. In choosing between keeping formal authority or delegating power to the agent, the principal trades off the benefit from control against the manager's loss of initiative.

The first result of the paper states that the principal will find it optimal to give the manager formal power only when profits of the firm take intermediate values. When profits are low, the principal's stakes are low and she invests little in information acquisition. This in turn implies that the division manager is more likely to have real authority ex-post, and so it becomes unnecessary to give him formal authority ex-ante. On the other hand, when profits are high, the principal's investment in information acquisition will tend to be high, and the agent's initiative will be killed even when he is given formal power. In such a case, the principal is indifferent between keeping formal power or giving it away, so there is no gain in assigning formal authority to the division manager. Finally, there may exist intermediate levels of profits for which the principal finds it optimal to delegate formal power to the agent to induce him to invest in information acquisition.

We then solve for the general equilibrium (imposing free entry and factor market clearing). Firms enter the market until profits are driven down to cover the fixed costs. Interestingly, we find that product market competition (captured by the elasticity of substitution between different varieties) increases the stakes of the firm thereby influencing the behavior of the principal and the agent inside the firm. Firms require larger profits to enter the market when product market competition is tough. Furthermore, we find that product market competition is an important determinant of the equilibrium mode of organization. With an increase in competition the equilibrium firm organization moves from centralization of power (P-organization) to decentralization of power (A-organization) to a single managed firm (Dixit-Stiglitz firm). With an increase in competition firms require a larger level of profit to enter the market. Initially, with little competition, the stakes of the firm are low and the principal monitors little and does not kill the initiative of the agent. Hence, firms choose the P-organization. When competition keeps increasing, however, the stakes of the firm and the monitoring 
of the principal rises potentially destroying the intiative of the agent. The firm then delegates power to the agent to keep his initiative. When competition is very tough the entry stakes of the firm are so high that the principal wants control and the DS-firm emerges as the equilibrium organization.

Our model delivers further interesting results. First, in the general equilibrium of the closed economy, there exist a range of competition levels for which there are multiple equilibria, with all principals in the monopolistically competitive sector either delegating or not delegating power. Second, when two identical countries open up to trade this could induce convergence of corporate cultures. It remains, however, open to which organizational equilibrium the world economy converges.

This paper describes how international competition affects corporate organization in similar countries (North-North trade). In Marin and Verdier (2003a, $2003 \mathrm{~b}$ ) we introduce the AT-firm in an Helpman-Krugman model of trade in which countries differ in factor endowments. Surprisingly, we find that NorthSouth trade integration leads to a 'war for talent' inducing firms to empower their human capital workers. Hence, workers empowerment and the move to flatter corporate hierarchies emerge as an equilibrium in the world economy when the world economy is governed by both North-North trade as well as by North-South trade.

There is a small literature which introduces endogenous organizations in general equilibrium. In Mc Laren (2001) final goods producers and input suppliers face the choice between remaining separate firms or to merge to vertically integrated firms. The choice depends on the trade-off between the hold-up problem that input suppliers face relative to the costs of running a larger organization. The trade-off is driven by the thickness of the market for inputs. The more unintegrated firms are around the more likely it is that these firms will be potential buyers of inputs from independent suppliers increasing the attractiveness of unintegrated input supply. Thus, there is a negative externality from vertical integration which makes arm's length arrangements less feasible for others. International trade affects the trade-off between the hold-up problem and the governance costs of a larger organization by increasing the number of alternative buyers abroad making arms' lengt transactions more remunerative. Based on a search-theoretic concept of market thickness Kranton (1996) formalizes the idea of 'reciprocal exchange' as an alternative to market exchange in developing countries and shows that search externalities can give rise to multiple equilibria and inefficiencies in the 
choice between the two modes of organizations. Grossman and Helpman (2002) develop an equilibrium model of industrial organization which examines the likelihood of an equilibrium with outsourcing and vertical integration. They analyze the interaction between the degree of competition in the product market and the existence of an equilibrium with outsourcing. An equilibrium with outsourcing is most likely to exist when the excess costs of vertically integrated firms are large and the degree of product market competition is neither too large nor too small. ${ }^{4}$

The paper is organised in the following sections. In section 2 we examine the allocation of power inside the firm from a partial equilibrium perspective. We determine the firm's optimal firm organization in response to exogenous changes in the market environment. In section 3 we embed the theory of firm organization in a general equilibrium model in which differentiated consumer goods can be produced by firms with three types of organizations: a P-organization in which the CEO has formal decision control, an A-organization in which the CEO delegates decision power to lower management, and a single managed firm organization without an internal hierarchy. We characterize the equilibrium industrial structure and we show that mixed equilibria do not exist in which different types of firm organizations coexist in the economy. In section 4 we examine how changes in market competition affect the equilibrium mode of organization. We show that with an increase in competition the equilibrium firm organization moves from centralization of power to decentralization of power and finally to a single managed firm. Furthermore, we show that at intermediate levels of competition the economy will be characterized by an A-organizational equilibrium in which power is delegated to lower levels of the firms' hierarchy. Thus, workers empowerment and the move to flatter firm hierarchies are phenomena which emerge when competition is not too tough and not too weak. ${ }^{5}$ The firms' organizational decisions

\footnotetext{
${ }^{4}$ Legros and Newman (2000) examine organizations in a competitive market. They focus on the allocation of ownership in the presence of liquidity constraints. They find that the organization of all firms depends on the liquidity position of the marginal firm.

${ }^{5}$ In Grossman and Helpman (2002) an equilibrium with outsourcing emerges, as in our case, at an intermediate level of competition. The mechanism is quite different, though. In Grossman and Helpman, the outsourcing equilibrium arises from a trade-off of the costs of running a larger organization with the potential costs of buying an inflated input. In our model, the Aequilibrium arises from trading-off the CEO's control in the firm with the workers' initiative. In contrast, the literature examining competition and its effect on X-inefficiencies in firms based on agency problems does not always get a non-monotone relationship between cost reduction efforts and competition. However, this literature does not consider changes in firm organization in response to increased competitive pressures, see Schmidt (1997), Raith (2003) and Vives
} 
feature a strategic complementarity which can lead to multiple organizational equilibria. Two otherwise identical countries migth have different corporate cultures which will tend to converge when countries become more integrated into the world economy. Finally, in section 5 concludes.

\section{Power Dynamics inside the Firm}

We first start with a simple partial equilibrium model of the choice of firm organization. This building block will be useful later when we analyze the interaction between the power dynamics inside the firm and the market structure in a general equilibrium model of monopolistic competition.

Following Aghion and Tirole (1997), we consider a firm with the simplest hierarchy consisting of a CEO (the principal $\mathrm{P}$ ) hiring a division manager (the agent A) to implement a production project. There are $m$ potential and a priori identical projects (or ways to produce a good). Payoffs are ex ante unknown to both parties. Among the $m$ projects, there is one which yields the highest possible benefit $B$ for the principal and one which yields the highest possible benefit $b$ for the agent. Let $\alpha B$ be the principal's expected benefit when the agent's preferred project is implemented with $(0 \leq \alpha \leq 1)$. Similarly, $\beta b$ is the agent's expected benefit when the principal's preferred project is implemented with $(0 \leq \beta \leq 1)$. $\alpha$ and $\beta$ are congruence parameters between the principal and the agent capturing the degree of trust between the principal and the agent. The lower $\alpha$ and $\beta$ the lower is the mutual trust between the principal and agent.

$B$ and $b$ are supposed to be known ex ante though the parties do not know ex ante which project yields such payoff. We assume also that, among the $m$ projects, there are some with very high negative payoffs to both parties, implying that choosing randomly a project without being informed is not profitable to both agents who instead prefer to do nothing (project 0). This aspect, together with the fact that each uninformed party prefers to rubber-stamp the other informed's party suggestion to do nothing, implies that private information about payoffs

(2003). 
gives decision control to the informed party. In this case, the informed party has "real authority" rather than "formal authority". ${ }^{6}$

Parties may acquire information on the payoff structure in the following way. By spending some resource cost

$$
g_{P}(E)=g \frac{E^{2}}{2}
$$

the principal $P$ learns the payoff structure of all projects with probability $E$ and remains uniformed with probability $1-E$. Similarly, by exerting some effort

$$
g_{A}(e)=k e \text { with } e \in[0, \bar{e}], k<b
$$

the agent learns the payoff structure of all projects with probability $e$ and remains uninformed with probability $1-e .^{7}$

We assume that the principal is risk neutral and that the agent is infinitely risk averse with respect to income. Therefore, the agent is not responsive to monetary incentives and he agrees to receive a fixed wage $w$ equal to his opportunity cost. His incentives to gather information on projects will be directly related to the private non pecuniary benefit $b$ he gets from his "best" project. ${ }^{8}$

Decisions are taken in the following sequence. The principal allocates formal power to herself (P-organization) or to the agent (A-organization). Then the two parties collect information about projects' payoff simultaneously. The party who does not have decision power suggests a project (or nothing) to the other party. Finally, the party with power rubber stamps the other party's suggestion or selects

\footnotetext{
${ }^{6}$ As emphasized by Aghion and Tirole 1997, the amount of information acquisition is at the heart of the distinction between "formal" and "real" decision power within firms.

${ }^{7}$ We need the principal's and the agent's costs of effort to differ to derive Proposition 2 of a trade-off between control and initiative at intermediate levels of profits, see the dicussion on page 15 why this is the case. The insight of Proposition 2 remains, however, valid when the effort cost functions of the principal and the agent are reversed with the principal having linear costs of effort and the agent convex ones.

${ }^{8}$ What makes principals and agents inherently different is not adressed by our model. In fact, besides attitudes towards risk and cost of effort principals and agents do not differ in our model. This is not a model of entrepreneurship and occupational choice, but rather how power relations in organizations interact with market competition. We do not adress why and what are the incentives for these organizations to exist in the first place. See the discussion on pages 24 and 25 how the model makes sure that there is an equal number of principals and agents.
} 
an alternative project, or decides to do nothing. Hence, the party with formal authority, whenever informed, picks her preferred project. When she remains uninformed ex post, that party rubber-stamps the suggestion of the other party who, whenever informed, has real authority over the project choice and gets his preferred project implemented. When neither party has information on the payoff structure, no project is undertaken by the firm.

Let us look then at the equilibrium informational efforts of the two parties under the two organizations.

\subsection{P-organization}

We start with the case where the principal has formal power in the firm. The two parties' expected payoffs are then

$$
\begin{aligned}
& u_{P}=E B+(1-E) e \alpha B-g_{P}(E)-w \\
& u_{A}=E \beta b+(1-E) e b-g_{A}(e)
\end{aligned}
$$

With probability $E$, the principal becomes fully informed about her payoffs and picks her preferred project with monetary payoff $B$, while the agent receives only the expected private benefit $\beta b$. With probability $1-E$, the principal remains uninformed about payoffs. The agent may then learn with probability $e$ the payoff structure and suggest his best project to the principal (who accepts it). The principal receives a monetary payoff $\alpha B$ while the agent gets his best private benefit $b$. Or the agent may remain also uninformed in which case, no project is undertaken.

The first order conditions of the two parties with respect to efforts $E$ and $e$ are

$$
\begin{aligned}
& \text { Principal: } B(1-e \alpha)=g E \\
& \text { Agent: } \begin{aligned}
e & =\bar{e} \text { if } k \leq b(1-E) \\
& =0 \text { if } k>b(1-E)
\end{aligned}
\end{aligned}
$$

The conditions highlight the trade off between the principal's control and the agent's initiative. The principal supervises more the higher her stake in the project (the larger $B$ ), the larger the conflict of interest between the principal and the agent (the lower the congruence $\alpha$ ) and the lower the agent's effort $e$. The agent, in turn, has more initiative the higher her stake (the larger $b$ ) and the lower the 
principal's interference (the lower $E$ ). Thus, control comes with the cost of loosing the agent's initiative.

There are three possible Nash equilibria in effort levels. We select the equilibrium with the highest agent's effort which is also the one preferred by the principal. $^{9}$

The Nash equilibrium level of efforts under the P-organization is
a) $e_{P}^{*}=\bar{e}$, and $E_{P}^{*}=\frac{B(1-\bar{e} \alpha)}{g} \quad$ when $B \leq \widetilde{B}_{P}(\alpha)$
b) $e_{P}^{*}=0$, and $E_{P}^{*}=\frac{B}{g} \quad$ when $B>\widetilde{B}_{P}(\alpha)$

with

$$
\widetilde{B}_{P}(\alpha)=\frac{g(1-k / b)}{1-\bar{e} \alpha}
$$

$\widetilde{B}_{P}(\alpha)$ captures the threshold level of profits at which the agent's initiative is killed under the P-organization. For monetary payoffs over the threshold level $\widetilde{B}_{P}(\alpha)$, the principal exerts so much control (i.e. the effort $E_{P}^{*}$ ) that he kills the initiatives of the agent to acquire information by himself.

From this discussion, we can finally derive the equilibrium expected utility of the principal under the P-organization as

$$
\begin{aligned}
u_{P}^{*} & =E_{P}^{*} B+\left(1-E_{P}^{*}\right) e_{P}^{*} \alpha B-g \frac{\left(E_{P}^{*}\right)^{2}}{2}-w \\
& =g \frac{\left(E_{P}^{*}\right)^{2}}{2}+e_{P}^{*} \alpha B-w
\end{aligned}
$$

\subsection{A-organization}

Consider now the case where the principal has delegated decision control to the agent and thus the agent has formal authority. Now the principal is prevented

\footnotetext{
${ }^{9}$ For a discussion of the three Nash equilibria see Aghion and Tirole 1997.
} 
from overruling the agent's decision when both have acquired information. The two parties' expected payoffs are then

$$
\begin{aligned}
& v_{P}=e \alpha B+(1-e) E B-g_{P}(E)-w \\
& v_{A}=e b+(1-e) E \beta b-g_{A}(e)
\end{aligned}
$$

Now the agent chooses his preferred project when informed. When the principal is informed and the agent is uninformed, the principal suggests her preferred project, which is then implemented by the agent.

The analysis is similar to the one for the P-organization. We get the following characterization of the Nash equilibrium effort levels

$$
\begin{aligned}
& \text { a) } e_{A}^{*}=\bar{e} \text { and } E_{A}^{*}=\frac{B(1-\bar{e})}{g} \text { when } B \leq \widetilde{B}_{A} \\
& \text { b) } e_{A}^{*}=0 \text { and } E_{A}^{*}=\frac{B}{g} \text { when } B>\widetilde{B}_{A}
\end{aligned}
$$

with

$$
\widetilde{B}_{A}=\frac{g(1-k / b)}{\beta(1-\bar{e})}
$$

$\widetilde{B}_{A}$ is the critical profit level at which the agent's initiative is killed under the A-organization. Above the threshold level $\widetilde{B}_{A}$ the principal's stakes are so high that she acquires information $E_{A}^{*}$ leading to a high probability of intervention which, in equilibrium, leads to minimum agent's effort $e_{A}^{*}=0$.

Note however that

$$
\widetilde{B}_{A}=\frac{g(1-k / b)}{\beta(1-\bar{e})}>\frac{g(1-k / b)}{1-\bar{e} \alpha}=\widetilde{B}_{P}(\alpha)
$$

As $\widetilde{B}_{A}>\widetilde{B}_{P}(\alpha)$, A's initiative is killed already at a lower profit level under the $\mathrm{P}$-organization than under the A-organization. The reason is that under the Afirm the agent has formal authority and therefore has better effort incentives than when the principal has formal authority. Hence, it requires a larger principal's effort to kill the initiative of the agent under the A-firm than under the P-firm. Consequently, the threshold level of profits of the principal at which the agent's effort is shut-off can go up under the A-firm as compared to the P-firm. 


\subsection{Optimal Firm Organization}

We now summarize and compare the different modes of organization for different profit levels of the principal. Three cases can be distinguished.

Case 1: $B \leq \widetilde{B}_{P}(\alpha)$ (low profits)

The utility levels of the principal under the two forms of organization are simply

$$
u_{P}^{*}=g \frac{\left(E_{P}^{*}\right)^{2}}{2}+e_{P}^{*} \alpha B-w \quad \text { and } \quad v_{P}^{*}=g \frac{\left(E_{A}^{*}\right)^{2}}{2}+e_{A}^{*} \alpha B-w
$$

Given that $e_{P}^{*}=e_{A}^{*}=\bar{e}$, and that $E_{P}^{*}>E_{A}^{*}$ in this regime, it follows that $u_{P}^{*}>v_{P}^{*}$. Thus, the P-organization dominates the A-organization. At this profit level there is no trade-off between the principal's control and the agent's initiative. When $B$ is low, the principal monitors and intervenes little under both organizations because her stakes are small. Therefore, both organizations give sufficient effort incentives to the agent. However, the principal prefers the P-organization over the A-organization, since the former gives her more control over the firm.

Case 2: $\widetilde{B}_{P}(\alpha)<B \leq \widetilde{B}_{A}$ (intermediate profits)

At this profit level, the P-organization kills the agent's effort $e_{P}^{*}=0$, while he exerts maximal effort $e_{A}^{*}=\bar{e}$ under the A-organization. Thus, the principal's expected utilities under the two organizations, respectively are given by

$$
u_{P}^{*}=\frac{B^{2}}{2 g}-w \text { and } v_{P}^{*}=\frac{(1-\bar{e})^{2} B^{2}}{2 g}+\bar{e} \alpha B-w
$$

$u_{P}^{*}>v_{P}^{*}$ and thus the principal prefers the $\mathrm{P}$-firm over the A-firm when

$$
B>\bar{B}(\alpha)=\frac{2 g \alpha}{2-\bar{e}}
$$

$\bar{B}(\alpha)$ is the critical profit level at which the principal is indifferent between the Porganization and the A-organization. When $B$ is larger than $\bar{B}(\alpha)$, the principal prefers to exert more control with no agent's initiative to less control while keeping the agent's initiative. 
At intermediate profits the optimal firm organization switches in the following way. i) For $\bar{B}(\alpha) \leq \widetilde{B}_{P}(\alpha)$, the P-organization with agent's effort dominates the A-organization. ii) For $\widetilde{B}_{P}(\alpha)<\bar{B}(\alpha) \leq \widetilde{B}_{A}$, on $\left[\widetilde{B}_{P}(\alpha), \bar{B}(\alpha)\right]$ the A-organization dominates, and on $\left[\bar{B}(\alpha), \widetilde{B}_{A}\right]$ the P-organization without agent's effort is the optimal firm organization. iii) For $\widetilde{B}_{A}<\bar{B}(\alpha)$ the A-organization dominates the P-organization.

Case 3: $\widetilde{B}_{A}<B$ (high profits)

At this profit level there is again no trade off between control and initiative. Both firm organizations kill the agent's initiative and provide the same level of control to the principal. Hence, they are just equivalent. However, if we allow for the lowest agent's effort $e$ to be in the interval $[\underline{e}, \bar{e}]$ with $\underline{e}$ small but strictly positive, then the $\mathrm{P}$-organization dominates the A-organization. There is more control under the P-firm. Therefore, we consider the P-firm to dominate the $A$-firm in this regime.

We summarize the preceding discussion in proposition 2.1. It states the optimal firm organization as a function of the principal's monetary payoff $B$ when her preferred project is implemented.

Proposition 2.1. Let $B_{\min }(\alpha)=\operatorname{Min}\left\{\bar{B}(\alpha) ; \widetilde{B}_{A}\right\}$

i) If $B_{\min }(\alpha)<\widetilde{B}_{P}(\alpha)$ the P-organization dominates the A-organization for all values of $B$

ii) If $\widetilde{B}_{P}(\alpha)<B_{\min }(\alpha)$, the firm moves from the P-organization with agent's initiative to an $A$-organization to a P-organization without agent's initiative as the profit level increases.

- For $B \leq \widetilde{B}_{P}(\alpha)$ the $P$-firm dominates the $A$-firm with $e_{P}^{*}=\bar{e}$ and $E_{P}^{*}=$ $\frac{B(1-\alpha \bar{e})}{g}$

- For $\widetilde{B}_{P}(\alpha)<B<B_{\min }(\alpha)$ the A-firm dominates the $P$-firm with $e_{A}^{*}=$ $\bar{e}$ and $E_{A}^{*}=\frac{B(1-\bar{e})}{g}$

- For $B_{\min }(\alpha) \leq B$ the $P$-firm dominates the $A$-firm with $e_{P}^{*}=0$ and $E_{P}^{*}=\frac{B}{g}$

Intuitively, the mode of organization matters for incentives inside the firm at intermediate levels of profits only. At low and high profit levels there is no tradeoff between control and initiative. At low profit levels, the principal monitors and 
intervenes little because her stakes are small and she cares little. Therefore, the P-organization gives sufficient initiative to the agent. The P-firm dominates the A-firm, because it gives the principal more power over the organization. At high profit levels, the principal's stakes are so large that she intervenes even under the A-organization leading to minimum effort by the agent in both firm organizations. Since $\mathrm{P}$ has more control under the P-firm compared to the A-firm, the principal prefers the P-firm. At intermediate levels of profits there is a trade-off between control and initiative. At some intermediate value of $B$, the A-firm dominates to give the agent sufficient incentives for initiative. When the profit level $B$ keeps increasing however, the gain emanating from the agent initiative is overcome by the loss of control of the principal and the P-firm with no incentives for the agent becomes the optimal organization.

The comparative static results of Prosposition 2 remain valid when the effort cost functions of the principal and the agent are reversed with the principal having linear costs of effort and the agent convex ones. At intermediate levels of profits the agent's effort response to changes in profits is low with quadratic costs of efforts, but it is still crowded out by the principal's effort because in these range of profits the principal does so much monitoring when she has linear costs of effort. More generally, to get a trade-off between control and initiative at intermediate levels of profits we need two things to hold. First, the principal's effort has to be bounded from above $\bar{E}=1$ so that the principal's increased effort does not compensate for the decreased effort of the agent. Second, the principal's effort response to changes in profits is strong or the agent's effort response to the principal's effort is strong. Thus, in order for the intuition of Proposition 2 to work either of the two parties may have linear costs of effort and the other convex costs of effort. When both agents have quadratic costs of effort the trade-off may disappear. It will depend on the size of the elasticity of effort of one party to the other. But it will still be the case that when there is a trade-off between control and initiative it has to be at intermediate profit levels.

¿From our previous analyses we have derived three modes of firm organizations. First, the formal P-firm in which the agent's initiative is sustained. In this organization the firm has an internal hierarchy with two layers of management (the CEO and the division manager) and the decision power is centralized at the top of the organization. One can think of this mode of organization as integration in which the CEO and the division manager are merged in one firm. Second, the formal A-firm in which the CEO delegates formal control to the division manager. In this organization the decision power is decentralized. The firm organization is 
less hierarchical and empowers workers at lower layers of the firm hierarchy. One can think of this mode of organization as outsourcing in which the CEO and the division manager run two independent firms. Third, the formal P-firm with no agent's initiative. In this case the corporation is run by a single manager (the principal) with no internal hierarchy. We denote the single managed firm with no internal hierarchy as the DS-organization. ${ }^{10}$

\section{General Equilibrium}

In this section we endogenize the principal's profit $B$ by letting firms compete for market shares in the product markets and for labor in the labor markets. This will allow us to analyze the interaction between the organization of the firm and market competition in general equilibrium. In order to do this, we embed the model of power inside the firm of the previous section in a general equilibrium framework with monopolistic competition.

Consider an economy with $L$ workers who can be employed at production as well as monitoring projects. Labor is taken as the numeraire with a wage rate $w=1$. There are $n$ firms (principals) with $n$ large enough to have monopolistic competition holding. In order to produce a good, each firm has to undertake a profitable production project which is a way to run the firm's production with a constant marginal cost technology. We embed our previous model of power inside the firm by assuming that there are ex ante $m$ alternative ways to produce the good. Thus, before starting to produce the firm needs to get informed about the cost parameters of the various ways of producing. In order to get the information and to monitor the project, the firm hires an agent who can undertake an effort $e$ to get the relevant information. The firm may also learn directly about the cost structure of the different projects by spending a labor resource cost $g E^{2} / 2$. As before we assume that out of all the possibilities, only two projects are worth doing from the point of view of the two parties within the firm. The "best project" for the firm (the principal) has marginal costs of production $c_{B}$ in terms of labor. The "best project" for the agent has marginal costs of production $c_{b}$ in terms of labor $^{11}$. We suppose that $c_{B}\left\langle c_{b}=\varphi c_{B}\right.$ with $\varphi>1$ so that there is no perfect

\footnotetext{
${ }^{10}$ We use the Dixit and Stiglitz (DS) model to introduce market competition among firms in the next section. Thus, the DS-firm will serve as a benchmark for comparison.

${ }^{11}$ We maintain here all the assumptions made in the partial equilibrium section.
} 
congruence between the firm and her agent. The idea here is that when the agent has control in the firm he may choose a project which generates high perks for him or which advances his career rather than a project which minimizes costs. ${ }^{12}$

Firms produce a continuum of $n$ different product varieties. On the demand side workers have preferences over these varieties of the type Dixit-Stiglitz ${ }^{13}$.

$$
u=\left[\int_{0}^{n} y(i)^{\gamma} d i\right]^{\frac{1}{\gamma}} \quad \text { with } 0 \leq \gamma \leq 1
$$

where $y(i)$ is consumption of variety $i$. The parameter $\gamma$ measures the degree of product differentiation, the larger $\gamma$ the less differentiated are the varieties of goods.

\subsection{Monopolistic competition and product market}

Given Dixit-Stiglitz preferences, the demand of each firm $i$ is of the form

$$
y(i)=A p(i)^{-\frac{1}{1-\gamma}}
$$

where $p(i)$ is the price of good $i$ and $A$ is given by

$$
A=\frac{R}{\int_{0}^{n} p(i)^{-\frac{\gamma}{1-\gamma}} d i}
$$

with $R$ as aggregate spending. Aggregate spending equals national income in the general equilibrium.

\footnotetext{
${ }^{12}$ We model the conflict of interest between the principal and her agent as an increase in costs rather than a proportional reduction in operating profits when the agent picks her preferred project, since the latter looks more like a hold-up problem rather than a conflict of interest between the principal and her agent. Modelling the power struggle as coming from projects which do not necessarily minimize costs appears to us to be more microfounded. Stealing profits is more of an issue when dealing with the problem of holdup.

${ }^{13}$ Note that, strictly speaking, to be consistent with the partial equilibrium analysis, the monitoring agents have to be also infinitely risk averse to avoid pecuniary incentives. This will be so when their preferences are an infinite concave transformation of the function $u$. Given then the agent's income $w=1$, one can still derive the demand for each good in the same way as for the other workers
} 
For a product with marginal cost of production $c(i)$, monopolistic profit maximization provides the standard mark-up relationship

$$
p(i)=\frac{c(i)}{\gamma}
$$

and profit levels can be written as

$$
\pi(i)=(1-\gamma) \gamma^{\frac{\gamma}{1-\gamma}} A[c(i)]^{-\frac{\gamma}{1-\gamma}}
$$

Taking the cost differential between the two organizations $c_{b}=\varphi c_{B}$ into account we can rewrite the principal's profit when her or the agent's best project is implemented, respectively, as in the partial equilibrium framework of section 2 with the following expressions for the congruence parameter $\alpha$ and the operating profit level of the principal $B$

$$
\alpha=\varphi^{-\frac{\gamma}{1-\gamma}} \quad \text { and } \quad B=(1-\gamma) \gamma^{\frac{\gamma}{1-\gamma}} A\left[c_{B}\right]^{-\frac{\gamma}{1-\gamma}}
$$

Notice that the trust parameter $\alpha$ is now related to the two parameters $\varphi$ and $\gamma$. The cost differential $\varphi=c_{b} / c_{B}$ measures by how much production costs of the firm $c(i)$ go up when the agent has control rather than the principal, $\varphi>1$. $\gamma$ captures the degree of competition in the product market, $0<\gamma<1$. The larger is $\gamma$ the more similar goods become and the better substitutes they are for each other (i.e. the larger is the elasticity of substitution between varieties $\sigma=1 /(1-\gamma))$. Thus, when $\gamma$ is close to one the market is very competitive. $\alpha$ declines with an increase in $\varphi$ or $\gamma$. The conflict of interest between the principal and the agent becomes larger when production costs increase when the agent has control rather than the principal (the larger is $\varphi$ ), and when competition in the product market is more intense (the larger is $\gamma$ ). When competition becomes more intense, a given cost differential between the A-firm and the P-firm translates into a larger differential in market shares and profits and thus delegating power becomes more costly to the firm.

\subsection{Labor market}

We turn now to the labor market. Firms hire an agent to supervise the production project and employ workers to produce the good. 
The firm's output is given by

$$
y(i)=\gamma^{\frac{1}{1-\gamma}} A[c(i)]^{-\frac{1}{1-\gamma}}
$$

From this, we can derive the total labor demand for each internal organization of the firm using the law of large numbers and the fact that the probability for a firm to run a production project with a unit labor cost $c(i)$ is also the fraction of firms having such a cost structure.

- Labor demand under P-organization with agent's effort.

Consider first the aggregate labor demand under the P-organization. It can be written as

$$
L_{P}^{D}=n\left[E_{P}^{*} c_{B} y_{B}+\left(1-E_{P}^{*}\right) e_{P}^{*} c_{b} y_{b}\right]+n\left[1+g \frac{\left(E_{P}^{*}\right)^{2}}{2}\right]
$$

The first term in the first bracket is the labor demand from firms for which the principal's preferred project has been implemented. Their fraction is (by the law of large numbers) $E_{P}^{*}$ under the P-organization with a firm's labor demand $c_{B} y_{B}$. Similarly, the second term in the first bracket is the labor demand from firms for which the agent's preferred project has been implemented. Their fraction is $\left(1-E_{P}^{*}\right) e_{P}^{*}$ under the P-organization with an individual firm's labor demand $c_{b} y_{b}$. In the second bracket of the RHS, the number 1 reflects the hiring of the monitoring agent for each firm while the term $g \frac{\left(E_{P}^{*}\right)^{2}}{2}$ reflects the labor input of direct monitoring by the principal. Notice, that the aggregate labor demand of the economy depends on the economy wide mix of real P-firms and real A-firms (as compared to formal P-firms and formal A-firms). The reason is that the firm organization affects the firm's production costs and with it its output level and its individual labor demand. ${ }^{14}$ Substituting $y_{B}, y_{b}$ and $c_{b}$ gives

$$
L_{P}^{D}=n A \gamma^{\frac{1}{1-\gamma}}\left[E_{P}^{*}+\left(1-E_{P}^{*}\right) \alpha e_{P}^{*}\right]\left[c_{B}\right]^{-\frac{\gamma}{1-\gamma}}+n\left[1+g \frac{\left(E_{P}^{*}\right)^{2}}{2}\right]
$$

which can be rewritten as

$$
L_{P}^{D}=n \frac{\gamma B}{1-\gamma}\left[E_{P}^{*}+\left(1-E_{P}^{*}\right) \alpha e_{P}^{*}\right]+n\left[1+g \frac{\left(E_{P}^{*}\right)^{2}}{2}\right]
$$

\footnotetext{
${ }^{14}$ Note that even under the formal P-organization there will be a share of real A-firms in the economy, when the principal in these firms decides not to get informed about the project in which case the agent has real authority (a real A-firm).
} 
Clearly, this labor demand function holds for regions of the profit levels $B$ for which the P-organization dominates. Using proposition 2.1 (3.5) holds for

$$
B<\tilde{B}_{P}(\alpha) \text { and } E_{P}^{*}=\frac{B(1-\bar{e} \alpha)}{g}, e_{P}^{*}=\bar{e}
$$

Substituting in (3.5), gives finally the following aggregate labor demand

$$
L_{P}^{D}=n\left[\frac{B^{2}\left(1-e_{P}^{*} \alpha\right)^{2}}{2 g} \frac{1+\gamma}{1-\gamma}+\frac{\gamma}{1-\gamma} \alpha e_{P}^{*} B+1\right]
$$

- Labor demand under A-organization with agent's effort

Consider next the aggregate labor demand under the A-organization. As before, it can be written as

$$
\begin{aligned}
L_{A}^{D} & =n\left[e_{A}^{*} c_{b} y_{b}+\left(1-e_{A}^{*}\right) E_{A}^{*} c_{B} y_{B}\right]+n\left[1+g \frac{\left(E_{A}^{*}\right)^{2}}{2}\right] \\
& =n \frac{\gamma B}{1-\gamma}\left[e_{A}^{*} \alpha+\left(1-e_{A}^{*}\right) E_{A}^{*}\right]+n\left[1+g \frac{\left(E_{A}^{*}\right)^{2}}{2}\right]
\end{aligned}
$$

This aggregate labor demand function holds for regions of the profit level $B$ for which the A-organization dominates. Using again proposition 2.1, this holds when

$$
\widetilde{B}_{P}(\alpha)<B<\bar{B}(\alpha) \text { and } E_{A}^{*}=\frac{B(1-\bar{e})}{g}, e_{A}^{*}=\bar{e}
$$

Again substituting (3.9) in (3.8) provides

$$
L_{A}^{D}=n\left[\frac{B^{2}\left(1-e_{A}^{*}\right)^{2}}{2 g} \frac{1+\gamma}{1-\gamma}+\frac{\gamma}{1-\gamma} \alpha e_{A}^{*} B+1\right]
$$

- Labor demand under DS-organization with no agent's effort.

Under the DS-organization only the principal runs the firm and she is the only agent who engages in information collection. Production can occur only when information on projects is revealed. The aggregate labor demand under this benchmark regime can be written as

$$
L_{0}^{D}=n\left[E_{0}^{*} c_{B} y_{B}\right]+n\left[1+g \frac{\left(E_{0}^{*}\right)^{2}}{2}\right]
$$


The first term in the first bracket is the labor demand emanating from variable costs of production from firms which produce effectively. Their fraction is (by the law of large numbers) $E_{0}^{*}$ (the probability for the principal to get the relevant information on the projects' payoffs) with a firm's labor demand $c_{B} y_{B}$. The second bracket of the RHS, describes the labor demand emanating from the fixed costs of production. The number 1 reflects the hiring of the monitoring agent for each firm. ${ }^{15}$ The term $g \frac{\left(E_{0}^{*}\right)^{2}}{2}$ reflects the labor cost of direct monitoring by the principal, given that he is the only one to actively search for information.

Substitution again gives :

$$
L_{0}^{D}=n A \gamma^{\frac{1}{1-\gamma}} E_{0}^{*}\left[c_{B}\right]^{-\frac{\gamma}{1-\gamma}}+n\left[1+g \frac{\left(E_{0}^{*}\right)^{2}}{2}\right]
$$

which can be rewritten as:

$$
L_{0}^{D}=n \frac{\gamma B}{1-\gamma} E_{0}^{*}+n\left[1+g \frac{\left(E_{0}^{*}\right)^{2}}{2}\right]
$$

Clearly, this labor demand function holds for regions of profits $B$ for which the DS-organization dominates. Using proposition 2.1 (3.11) holds for

$$
B>\bar{B}(\alpha) \text { and } E_{0}^{*}=\frac{B}{g},
$$

Substitution in (3.11), yields finally the following aggregate labor demand

$$
L_{0}^{D}=n\left[\frac{B^{2}}{2 g} \frac{1+\gamma}{1-\gamma}+1\right]
$$

The labor market clearing condition can then be generally stated as

$$
L_{i}^{D}=L \text { for } i \in\{P, A, 0\}
$$

It is useful to compare here the three labor demand functions $L_{P}^{D}, L_{0}^{D}, L_{A}^{D}$ under the three organizations. Notice from (3.7), (3.10), and (3.13) that for a given value of $B$ labour demand can be ranked as $L_{0}^{D}>L_{P}^{D}>L_{A}^{D}$. The reason is that under the DS-firm the principal's labor input for information acquisition is largest, since

\footnotetext{
${ }^{15}$ Though the agent is useless for the principal under the DS-organization, he nevertheless has to be paid his reservation utility level because of contract incompleteness ex ante.
} 
there is no agent around as captured by the term $g \frac{\left(E_{0}^{*}\right)^{2}}{2}$ and lowest under the A-organization, with the P-firm with agent's effort in between. The extra effort by the principal under the P-firm (with and without agent's initiative) leads to lower marginal costs of production, larger output and thus larger labor demand compared to the A-firm. The A-firm is most efficient from an informational point of view and least efficient from a production cost point of view. The reverse is the case for the DS-firm. Information acquisition effort by the agent cannot be contracted upon ex ante when the agent is hired. Therefore, the DS-firm without agent's effort is the least efficient organization from an informational point of view. The reason is that in the P-firm with agent's effort and in the A-firm two people are acquiring information about projects and thus there is a higher chance that a good project is discovered than when the principal does it all by herself.

\subsection{Organizational Equilibrium with Free Entry}

We turn now to characterize the equilibrium industrial structure and the associated organization within firms. The timing of events is the following. In a first stage, firms decide whether or not to enter the market and to hire an agent to monitor projects. At this stage, there is free entry. In a second stage, firms decide who has formal power in the organization by choosing between the formal P-firm and the formal A-firm. In a third stage, information collection efforts are realized by the two parties and a project is selected. This, in turn, determines who has real power in the organization. Finally there is production, consumption and labor market clearing.

To describe the industrial structure of the economy we use the free entry condition for the monopolistic sector. This condition can be written as $\operatorname{Max}\left\{U_{P}(B)\right.$, $\left.U_{A}(B), U_{0}(B)\right\}=w=1$ where $U_{P}(B), U_{A}(B)$, and $U_{0}(B)$ are the profit levels of the firm gross of the wage of the agent, respectively under each internal organization $P, A$ or $D S^{16}$ The "Max" argument in the free entry condition reflects the fact that each firm decides about its optimal type after market entry.

\footnotetext{
${ }^{16}$ With the previous notation these profit levels are

$U_{P}(B)=u_{P}+w=g \frac{\left(E_{P}^{*}\right)^{2}}{2}+e_{P}^{*} \alpha B=\frac{B^{2}(1-\alpha \bar{e})^{2}}{2 g}+\bar{e} \alpha B$

$U_{A}(B)=u_{A}+w=g \frac{\left(E_{A}^{*}\right)^{2}}{2}+e_{A}^{*} \alpha B=\frac{B^{2}(1-\bar{e})^{2}}{2 g}+\bar{e} \alpha B$

$U_{0}(B)=u_{0}+w=g \frac{\left(E_{0}^{*}\right)^{2}}{2}=\frac{B^{2}}{2 g}$
} 
Three types of free entry equilibria are possible.

i) Equilibrium with P-organization and $e_{P}^{*}=\bar{e}$

The free entry condition in such a regime is

$$
U_{P}(B)=g \frac{\left(E_{P}^{*}\right)^{2}}{2}+\bar{e} \alpha B=1
$$

The endogenous values $\left(B, n, E_{P}^{*}, e_{P}^{*}\right)$ determining an equilibrium in this regime are then given (3.7) and (3.15). After substituting, the free entry condition and the labor market clearing condition can be restated as

$$
\frac{B^{2}(1-\alpha \bar{e})^{2}}{2 g}+\bar{e} \alpha B=1 \quad \text { and } \quad L=\frac{n}{1-\gamma}\left[\frac{B^{2}(1-\alpha \bar{e})^{2}}{2 g}+1\right]
$$

The free entry condition gives a unique positive solution $B_{P}=B_{P}^{*}(\alpha)$ which is the profit level required to make a firm indifferent between entering and not entering the market as a P-firm. Substituting into the labor market clearing condition provides then the equilibrium number of firms $n_{P}^{*}$ as

$$
n_{P}^{*}=\frac{(1-\gamma) L}{\left[\frac{\left(B_{P}^{*}\right)^{2}(1-\alpha \bar{e})^{2}}{2 g}+1\right]}
$$

Obviously, an equilibrium in this regime exists if and only if $B_{P}^{*}(\alpha) \leq \widetilde{B}_{P}(\alpha)$. As is well known from the Dixit and Stiglitz model, the number of varieties $n_{P}^{*}$ depend on the size of the country $L$ and on the degree of market power $\gamma$ as given in the numerator. ${ }^{17}$ With an increase in $\gamma$ firms' market power declines (product varieties become more similar and are better substitutes for each other) and thus firms charge lower mark-ups over marginal costs. Output per firm increases and thus, a smaller number of firms can be sustained in equilibrium. Furthermore, the number of firms decline with the fixed costs of market entry (with the costs of information collection by the principal and the agent) as given by the denominator of the expression. The fixed costs of market entry increase with an increase in the conflict of interest inside the firm (with a decline in $\alpha$ ) since firms will require a larger level of profits to enter the market.

\footnotetext{
${ }^{17} \mathrm{An}$ increase in country size leads to an increase in the number of firms without changing output per firm. This is a well known property of the DS-model.
} 
The free entry conditions (3.15), (3.18) and (3.21) and the labor market clearing condition (3.14) make sure that there are an equal number of principals and agents. The free entry conditions determine the number of firms and the number of principals. Principals then hire from the pool of labor supply workers for production and workers for control (agents). The wage rate adjusts so that there are an equal number of principals and agents and all the remaining workers are hired as production workers. The alternative occupation for an agent is to become a production worker. We assume here a somewhat myopic behavior of agents. Ex ante workers are indifferent whether they become control workers or production workers. Ex post when hired as control workers, agents learn about the non monetary benefit they have from being control workers. Ex post they prefer to control rather than to produce.

ii) Equilibrium with A-organization and $e_{A}^{*}=\bar{e}$

The free entry condition in such a regime is

$$
U_{A}(B)=g \frac{\left(E_{A}^{*}\right)^{2}}{2}+\bar{e} \alpha B=1
$$

The endogenous values $\left(B, n, E_{A}^{*}, e_{A}^{*}\right)$ determining an equilibrium in this regime are then given by (3.9), (3.10), and (3.18). After substitution, the free entry condition and the labor market clearing condition can be expressed as

$$
\frac{B^{2}(1-\bar{e})^{2}}{2 g}+\bar{e} \alpha B=1 \quad \text { and } \quad L=\frac{n}{1-\gamma}\left[\frac{B^{2}(1-\bar{e})^{2}}{2 g}+1\right]
$$

The free entry condition gives a unique positive solution for $B_{A}^{*}(\alpha)$ which is then substituted into the labor market clearing condition. This then provides the equilibrium number of firms $n_{A}^{*}$ as

$$
n_{A}^{*}=\frac{(1-\gamma) L}{\left[\frac{\left(B_{A}^{*}\right)^{2}(1-\bar{e})^{2}}{2 g}+1\right]}
$$

An equilibrium in this regime exists if and only if $\widetilde{B}_{P}(\alpha) \leq B_{A}^{*}(\alpha)<\bar{B}(\alpha)$.

iii) Equilibrium with DS-organization and $e_{P}^{*}=0$ 
Finally the free entry condition in such a regime is

$$
U_{0}(B)=g \frac{\left(E_{0}^{*}\right)^{2}}{2}=1
$$

After a similar calculation as in the cases before we obtain the equilibrium number of firms as

$$
n_{0}^{*}=\frac{1-\gamma}{2} L
$$

Such an equilibrium exists when $B_{P}^{*}=\sqrt{2 g}>\bar{B}(\alpha)$.

Notice that the $n_{0}^{*}$ equilibrium corresponds to the standard Dixit and Stiglitz equilibrium number of varieties with fixed costs of production equal to 2 , which consists of the labor input of 1 agent plus the principal's labor input for information acquisition $g\left(E_{P}^{*}\right)^{2} / 2=\left(B_{P}^{*}\right)^{2} / 2 g=1$.

Notice further, that from the conditions (3.16) and (3.19) we can rank the required equilibrium profit levels for a DS-firm $B_{0}^{*}$, an A-firm $B_{A}^{*}$, and, for a Pfirm with agent's effort $B_{P}^{*}$, respectively as $B_{0}^{*}>B_{A}^{*}>B_{P}^{*}$. The DS-firm requires the largest profit to enter the market, since information collection effort falls on the principal herself. Also, $B_{A}^{*}>B_{P}^{*}$, since some of the principal's profit gets lost under the A-organization (as measured by $\alpha$ ). Hence, the principal will have an incentive to enter the market only when sufficient high profits make sure that she is compensated for this loss in profits under the A-organization.

\section{Figure 1: The Firms' Profit Curves}

The equilibrium industrial structure under free entry in each regime as given by (3.17), (3.20), and (3.22) are illustrated graphically in Figure 1. From the figure it becomes apparent that the equilibria are stable and we can rule out mixed equilibria with some firms choosing an A-organization and others choosing a P-organization. The figure gives the different profit curves of the principal gross of the wage rate $w$ of the agent $U_{P}(B), U_{A}(B)$, and $U_{0}(B)$ under the three firm organizations $P, A$ and 0 in terms of the principal's payoff $\mathrm{B}$ (see footnote 14). $U_{P}(B)$ is above $U_{A}(B)$ and $U_{0}(B)$, while $U_{A}(B)$ cuts $U_{0}(B)$ from above at point $\bar{B}_{A}$. Above the threshold level of profits $\widetilde{B}_{P}$ the agent's initiative is killed under the P-organization. Thus, above $\widetilde{B}_{P}$ the P-firm with initiative stops to exist. As a result $U_{P}(B)$ above the profit level $\widetilde{B}_{P}$ is irrelevant and therefore drawn as a dotted line. The firm chooses the organization which $\operatorname{Max}\left[U_{P}(B), U_{A}(B), U_{0}(B)\right]$ 
which is given by the bold line in the figure. The figure illustrates the results of proposition 2.1. For $B<\widetilde{B}_{P}$, the principal chooses the P-firm with initiative as her optimal organization. For $\widetilde{B}_{P}<B<\bar{B}_{A}$, the optimal choice of organization is an A-firm, and for $\bar{B}_{A}<B$, the principal chooses the DS-firm as her optimal organization. The free entry condition is given by $\operatorname{Max}\left[U_{P}(B), U_{A}(B), U_{0}(B)\right]=$ $w=1$. The free entry equilibria are obtained by the intersection of the horizontal line $w=1$ with the gross profit curves $U_{P}(B), U_{A}(B), U_{0}(B)$. Three equilibria are possible depending on where the wage line crosses the gross profit curves. As it is drawn we have a $\mathrm{P}$-equilibrium in point $\mathrm{A}$, an A-equilibrium in point $\mathrm{D}$, and a DSequilibrium in point E. The figure demonstrates that the A-equilibrium is stable. For example, the A-equilibrium cannot be disturbed by a P-firm (with lower costs), since in the range of profits in which the A-firm emerges as an equilibrium, the P-firm with agent's initiative stops to be a a feasible organization. In the range of profits $\widetilde{B}_{P}<B<\bar{B}_{A}$ the principal can choose only between the A-organization and the DS-organization. Given that the A-organization yields higher profits, she chooses the former. ${ }^{18}$

\section{Market Competition and Firm Organization}

In this section we analyze how market competition affects the firm organization. In terms of the model, we look at whether changes in $\alpha$ and/or $\gamma$ make it more likely that a formal P-organization (with or without agent effort) or a formal A-organization will emerge in equilibrium.

It is useful to start the analysis of the interaction between the firm organization and market competition from a partial equilibrium perspective.

Figure 2: Optimal Firm Organization and Market Competition

The optimal firm organization is illustrated in Figure $2^{19}$. The $\tilde{B}_{P}(\alpha)$-curve relates the profit level to the incentives inside the firm and thus to the costs of producing. Recall that the $\tilde{B}_{P}(\alpha)$-curve represents the profit level at which

\footnotetext{
${ }^{18}$ From this argument it follows that the discussed stability of equilibria do not depend on the sequence of events. If we reverse the timing and let firms choose their firm types before market entry the same symmetric equilibria emerge.

${ }^{19}$ To simplify the exposition, Figure 2 only shows the case where $\bar{B}(\alpha)<\widetilde{B}_{A}$ for all $\alpha \in[0,1]$
} 
the effort incentive of the agent is killed under the P-organization. Thus, $\tilde{B}_{P}(\alpha)$ captures under the P-firm the costs of having a centralized mode of organization in terms of the loss of the agents initiative. $\tilde{B}_{P}(\alpha)$ is upward sloping in $\alpha$ (is downward sloping in $\gamma$ ) because with an increase in $\alpha$ the conflict of interest between the principal and the agent declines (the preferences between the principal and the agent become more similar). At a given profit level $B$, the principal intervenes less when the agent's preferred project is more congruent with her objectives, allowing the profit level at which the agent's initiative is killed to go up. In the area below the $\tilde{B}_{P}(\alpha)$-line the P-firm keeps the agent's initiative alive, while in the area above $\tilde{B}_{P}(\alpha)$ the agent does not exert any effort under the P-organization.

In Figure 2, the $\bar{B}(\alpha)$-line relates the profit level to the market environment of the firm and thus to the benefit of having a cost efficient mode of organization. Recall that the $\bar{B}(\alpha)$-line represents the profit level at which the principal is indifferent between the DS-firm with $e=0$ and the A-firm with the agents maximum initiative $\bar{e}$ (this is the relevant comparison because the principal always prefers the P-firm with $\bar{e}$ compared to the A-firm with $\bar{e})$. Thus, $\bar{B}(\alpha)$ captures the benefit of having a centralized mode of organization in terms of the firm's profit. $\bar{B}(\alpha)$ is downward sloping in $\gamma$ (is upward sloping in $\alpha$ ) because with an increase in $\gamma$ the market power of the firm declines. Thus, delegating power to the agent becomes more costly to the principal since a more costly mode of organization translates into a larger loss in profits. With a loss of power in the market, the firm wants more power inside the firm. Therefore, the threshold level of profits at which the principal is indifferent between the P-firm and the A-firm goes down with an increase in $\gamma$. In the area below the $\bar{B}(\alpha)$ - line the gain is larger when the agent's initiative is sustained even when the principal looses control. Thus, the principal prefers to delegate power to the agent. In the area above the $\bar{B}(\alpha)$-line the reverse is the case and thus the principal prefers to keep control.

We are now ready to analyze which organization will emerge in response to changes in the market environment. In the area $P_{1}$ below the $\tilde{B}_{P}(\alpha)$-curve the gain of control outweighs the costs and thus the principal chooses the P-firm as

and $B_{\min }(\alpha)=\bar{B}(\alpha)$. As is shown in the appendix, this is ensured when :

$$
\frac{2 \bar{e}}{2-\bar{e}}<\frac{(1-k / b)}{\beta(1-\bar{e})}
$$


her organization. At $B<\tilde{B}_{P}(\alpha)$ there are, in fact, no costs of control as the agent's initiative can be kept alive under the P-organization. In the area $A$, in between the two curves $\tilde{B}_{P}(\alpha)$ and $\bar{B}(\alpha)$, the costs of control outweigh the gain and thus the principal chooses the A-firm. In this area delegating control allows to maintain the agents initiative while at the same time delegating does not cost too much in terms of loss in profits, since $B<\bar{B}(\alpha)$. As can be seen, the area $A$ in which the A-organization is optimal increases in size with a decline in $\gamma$, since the smaller $\gamma$, the smaller the loss in profits which results from delegating power inside the firm. Finally, in the areas $P_{0}$ and $P_{2}$, the firm chooses the DS-organization since in the region $\tilde{B}_{P}(\alpha)<\bar{B}(\alpha)<B$ and at $\gamma$ close to one the principal's stakes are so high that the costs of having control become smaller relative to its gain. Market competition is so tough and/or profits are so high that the principal kills the initiative of the agent also under the A-firm, while delegating power incurs large losses in market shares.

Figure 3: Equilibrium Entry

We now turn to determine the profit level in the market. Profits are determined by market entry as given by the free entry conditions (3.15), (3.18), and (3.21). Firms enter the market until profits are driven down to zero. We now ask how the firm's incentive to enter the market is affected by market competition. In terms of the model, we look at how the equilibrium condition for free entry for the P-firm and the A-firm, respectively is affected by changes in $\gamma$ or $\alpha$. This is shown in Figure 3. Recall that the curves $B_{P}^{*}(\alpha)$ and $B_{A}^{*}(\alpha)$ are the required profit levels to enter the market as a P-firm and as an A-firm, respectively. Both curves slope down with $\alpha$ (slope up with $\gamma$ ) since both firms revenues increase with $\alpha$ (i.e. decrease with $\gamma$ ) and thus firms require a lower profit to enter the market. The monotone and increasing relationship between $B^{*}$ and $\gamma$ means that market competition increases the stakes of the firm and thus influences how competition affects the behavior inside the firm. ${ }^{20}$ The $B_{A}^{*}(\alpha)$-curve lies above the $B_{P}^{*}(\alpha)$-curve, since for any given $\alpha$ the $\mathrm{A}$-firm will have a harder time to survive competition in the product market as its price will be larger than the price of the P-firm. Therefore, the A-firm requires a higher profit to enter the market. When the firm does not face competition or preferences between the principal and the agent are perfectly congruent (when $\alpha=1$ or $\gamma=0$ ) the mode of organization

\footnotetext{
${ }^{20}$ In figure 3 the AT model meets the DS model in the sense that an increase in market competition (an increase in $\gamma$ ) can be treated in the same way as an increase in the stakes of the principal (an increase in $B$ ).
} 
stops to matter since all costs can be passed on to consumers without a loss in the market share (at $\alpha=1$ the two curves collapse to the same required profit value $\left.B_{A}^{*}(\alpha)=B_{P}^{*}(\alpha)\right)$.

Figure 4: Equilibrium Organization with Free Entry

Figure 4 combines the insights of Figure 2 and Figure 3 to analyze the equilibrium mode of organization under free entry ${ }^{21}$. Thus, the figure looks at how endogenous profits (given by the free entry conditions) interact with the firm's optimal choice of organization. The two curves $\tilde{B}_{P}(\alpha)$ and $\bar{B}(\alpha)$ from Figure 2 characterizing the optimal choice of internal organization are plotted as well as the two curves $B_{P}^{*}(\alpha)$ and $B_{A}^{*}(\alpha)$ from Figure 3 describing the free entry profit levels under the P-firm with agent's effort (i.e. $e=\bar{e}$ ) and under the A-firm. In addition, the horizontal line $B_{0}^{*}=\sqrt{2 g}$ is giving the free entry profit level under the DS-firm.

A free entry equilibrium P-organization with agent's effort is along the curve $B_{P}^{*}(\alpha)$ in the region of $\alpha$ in $\left[\alpha_{P}, 1\right]$. Below the $\tilde{B}_{P}(\alpha)$-curve firms want to choose the P-organization (we know this from Figure 2) and along the $B_{P}^{*}(\alpha)$-curve firms have an incentive to enter the market anticipating their choice of a P-organization. Thus, along the curve $B_{P}^{*}(\alpha)$ in the region of $\alpha$ in $\left[\alpha_{P}, 1\right]$ firms enter and choose the P-organization. Similarly, a free entry equilibrium A-organization with high agent's effort is along the curve $B_{A}^{*}(\alpha)$ and in between the two curves $\tilde{B}_{P}(\alpha)$ and $\bar{B}(\alpha)$. We know from Figure 2 that in between the curves $\tilde{B}_{P}(\alpha)$ and $\bar{B}(\alpha)$ firms choose the A-organization. Along the $B_{A}^{*}(\alpha)$ curve firms will have an incentive to enter the market anticipating their choice of an A-organization. Thus, firms enter and choose the A-organization along the $B_{A}^{*}(\alpha)$ curve in the region of $\alpha$ in $\left[\bar{\alpha}, \alpha_{A}\right]$. Finally, a free entry equilibrium DS-organization is along the flat curve $B_{0}^{*}=\sqrt{2 g}$ above the curve $\bar{B}(\alpha)$. We know from Figure 2 that above the curve $\bar{B}(\alpha)$ firms prefer the DS-organization to the A-organization with agent's effort. Along the $B_{0}^{*}$-curve profits are such that firms want to enter as DS-firms. ${ }^{22}$

\footnotetext{
${ }^{21}$ The precise derivation of figure 4 is given in the appendix.

${ }^{22}$ The figure can be used also to demonstrate that mixed equilibria can be ruled out almost surely. In order to have a mixed equilibrium firms must be indifferent between the A-organization and the DS-organization (recall that the P-organization with effort always dominates the Aorganization with effort). This requires $\mathrm{B}$ to be on the $\bar{B}(\alpha)$-line. But it also requires $\mathrm{B}$ to be
} 
The bold line in Figure 4 describes the nature of the free entry organizational equilibria as a function of the degree of competition $\gamma$ (or the degree of trust $\alpha$ ). Several points are worth noticing. First, at $\alpha=1$ and $\gamma=0$ the two organizations are equivalent from the point of view of the firm. At this parameter values, preferences of the principal and the agent are perfectly congruent. Either $\varphi=1$ and there is no cost differential between the two modes of organization. Or $\varphi>1$, but the cost differential does not matter for profits. Market competition is so weak at $\gamma=0$ that any organizational inefficiency can be passed on to consumers without loosing market share.

Second, with an increase in $\gamma$ (a decrease in $\alpha$ ) the equilibrium firm organization moves from centralization of power to decentralization of power and finally to a single managed firm (from a P-firm with agent effort to an A-firm to a DS-firm). Typically, with an increase in competition the firm requires a larger level of profit $B^{*}$ to enter the market under both organizations. This means that the stakes of the firm rise with more competition and thus the firm has a larger incentive to monitor projects. Initially, with little competition for values of $\alpha$ in the range of $\left[\alpha_{P}, 1\right]$, the firm's free entry stakes $B^{*}$ are not too high. Therefore, the firm's monitoring does not kill the initiatives of the agent even under the P-organization. Hence, firms choose the latter. However, when competition keeps increasing and $\gamma$ takes intermediate values, then the required stakes to enter the market are high enough to kill the initiative of the agent under the P-firm but not under the Afirm. This in turn means that there is a trade-off between control and initiative for the firm. As long as the free entry stakes are not too high (i.e. corresponding to values of $\alpha$ in $\left[\bar{\alpha}, \alpha_{A}\right]$ ), the A-organization will emerge as an equilibrium free entry outcome for each firm. Finally, as competition is increasing further (i.e. corresponding to values of $\alpha$ smaller than $\bar{\alpha}$ ), the required profit level for market entry increases further until the stakes for the firm become so high that the trade-off between control and initiative balances out in favor of control and the DS-firm emerges as the equilibrium organization.

Third, the model produces multiple equilibria for $\alpha$ in the range of $\left[\alpha_{P}, \alpha_{A}\right]$. At intermediate levels of competition one equilibrium mode of organization is the P-firm with high agent's effort and another equilibrium mode of organization is

on the $B_{A}^{*}(\alpha)$-curve in order for the firm to have an incentive to enter as an A-firm. This kind of situation can occur only in the figure when the two curves intersect at $\bar{\alpha}$. Hence, if at all a mixed equilibrium between the A-organization and the DS-organisation can occur only for one value of $\alpha=\bar{\alpha}$. 
the A-firm ${ }^{23}$. The reason for such multiple equilibria comes from a "strategic complementarity " among firms at the decision stage of optimal firm organization. At an intermediate level of competition the attractiveness between these two modes of organizations depends on the organizational decisions taken by other firms in the market. Each firm individually would choose the A-organization at this level of competition, since in between the curves $\tilde{B}_{P}(\alpha)$ and $\bar{B}(\alpha)$ the A-organization is optimal. However, when the firm anticipates at this stage that all the other firms will choose the P-organization, then, she also anticipates that the profit and cost level in the market will be low as well. Recall that P-firms have lower costs and thus require a lower profit level for market entry. Thus, the firm anticipates that it will be hard for her to survive competition with an A-organization. Therefore, market entry as an A-firm is not profitable and the firm's best choice after entry will be to choose a P-organization as well. Similarly, when the firm anticipates that all the other firms will choose the A-organization, then she expects to be a viable competitor in the market with an A-organization. Thus, the firm also opts for an A-organization after market entry. The multiplicity of organizational equilibria arise due to a coordination problem among firms which comes from the fact that the firm's choice of organization depends on her profits as well as on the profits of the other firms in the market. The other firms profit level, in turn, depends on what firm organization they have chosen. As aggregate costs in the market are determined by the composition of A-firms and P-firms in the market, the model produces a feedback mechanism by which the firm's organizational choice determines market conditions, which, in turn, influence an individual firm's choice of firm organization.

Note that the coordination problem among firms disappears for low and high levels of competition, outside the range of $\alpha$ of $\left[\alpha_{P}, \alpha_{A}\right]$. When competition is low (in the range of $\alpha$ of $\left[\alpha_{A}, 1\right]$ the firm's organizational choice does not depend on other firms' organizational decision, because individual and aggregate costs do not matter too much for how well the firm is doing in the market. When competition is tough (in the range of $\alpha$ of $\left[\bar{\alpha}, \alpha_{P}\right]$ ) the option for the firm to choose a Porganization with high agent's effort disappears altogether and thus, as our firm, all the other firms in the market will choose the A-organization as well and they

\footnotetext{
${ }^{23}$ There is also a third equilibrium which corresponds to the case where the P-firm has a third Nash "interior" equilibrium in terms of the agent's effort and the principal's effort $e_{P}^{*}=$ $\frac{1}{\alpha}\left(1-\frac{g\left(1-\frac{k}{b}\right)}{B}\right), E_{P}^{*}=1-\frac{k}{b}$. This Nash equilibrium has been selected away because it was dominated by the agent's high effort equilibrium $e_{P}^{*}=\bar{e}, E_{P}^{*}=(1-\alpha \bar{e}) B / g$
} 
will not find it profitable to enter as P-firms. Thus, in either case, at low and high levels of competition, there is no need to coordinate actions among firms.

\section{Conclusion}

In this paper we examine how market competition interacts with the firms' mode of organization in general equilibrium. Market competition changes the behavior of the people inside the firm. With an increase in market competition the conflict of interests between different layers of management becomes more costly to the firm as the power struggle translates in a larger loss in market share. As the stakes rise, the CEO gets more involved in the decisions taken and monitors more inside the firm when her market power is eroded by competition. The increase in the CEO's control in the firm comes, however, with the potential costs of loosing the initiative and enthusiasm of lower level management. Under these circumstances, it may be worthwile for the CEO to change the mode of organization and to delegate decision power to lower levels of management to preserve its initiative. The empowerment of management involves then a shift to a firm organization with larger production costs. Thus, to empower workers at lower levels of the firm hierarchy a profit maximizing corporation might not opt for the 'leanest' organization which minimizes costs.

Our model produces multiple equilibria which arise out of a strategic complementarity among firms organizational decisions. Firms organizational choice determines market conditions, which in turn, influence an individual firm's choice of firm organization. This feedback mechanism can account for why two otherwise identical countries might have different corporate cultures (like i. e. centralized corporate organization in Germany and decentralized corporate organization in the US). Firms in one country choose a particular corporate organization because they expect other firms to choose this organization. ${ }^{24}$ Globalization leads to a convergence in corporate cultures across countries. This may result in merger waves (a shift from an A-organization to a P-organization) or in waves of outsourcing (a move from a P-organization to an A-organization) when countries become more

\footnotetext{
${ }^{24}$ For the role of history versus expectations, see Krugman (1991).
} 
integrated into the world economy as the corporate sector reorganizes in response to an increase in international competition. ${ }^{25}$

\footnotetext{
${ }^{25}$ In Mc Laren (2001) international trade can lead to an increase in arm's length trade which tends to be 'internationally contagious'. In his model international trade lowers the hold-up problem that input suppliers face, which in turn, leads to an increase in arm's length trade. In Legros and Newman (2000) a change in the liquidity positions of firms can induce economy wide organizational changes.
} 


\section{References}

[1] P. Aghion and J. Tirole. 1995. Some Implications of Growth for Organizational Form and Ownership Structure. European Economic Review 39. pp. 440-455.

[2] P. Aghion and J. Tirole. 1997. Formal and Real Authority in Organizations. Journal of Political Economy. 105: 1. pp 1-29.

[3] Chris Argyris. 1998. Empowerment: The Emperor's New Clothes. Harvard Business Review. May-June. pp 98 - 105.

[4] P. Bolton and D.S. Scharfstein.1998. Corporate Finance, the Theory of the Firm, and Organizations. Journal of Economic Perspectives. 12: 4. pp. 95114.

[5] A. K. Dixit and J. E. Stiglitz. 1977. Monopolistic Competition and Optimum Product Diversity. American Economic Review. 67, pp. 297-308.

[6] G. Grossman and E. Helpman. 2002. Integration vs. Outsourcing in Industry Equilibrium. Quarterly Journal of Economics. forthcoming.

[7] S. J. Grossman and O. Hart .1986. The Costs and Benefits of Ownership: A Theory of Vertical and Lateral Integration. Journal of Political Economy. 94. pp. 691-719.

[8] O. Hart and J. Moore. 1990. Property Rights and the Nature of the Firm. Journal of Political Economy. 98. pp. 1119-1158.

[9] B. Holmstrom. 2000. Corporate Restructuring: Markets versus Managers. Lecture given at the University of Munich. Mimeo.

[10] B. Holmstrom and St. N. Kaplan. 2001. Corporate Governance and Merger Activity in the United States. Journal of Economic Perspectives. 15: 2, pp. 121-144.

[11] R. E. Kranton. 1996. Reciprocal Exchange: A Self-Sustaining System. American Economic Review 86: 4, pp 830-51.

[12] P. Krugman. 1991. History versus Expectations. Quarterly Journal of Economics. 106:2, pp. 651-67. 
[13] L. Lang and R. Stulz. 1994. Tobin's Q, Corporate Diversification, and Firm Performance. Journal of Political Economy, 102. pp. 1248-1280.

[14] P. Legros and A.F. Newman. 2000. Competing for Ownership. ECARES. Université Libre de Bruxelles. Mimeo. July.

[15] D. Marin and Th. Verdier. 2003a. Globalization and the 'New Enterprise'. Journal of the European Economic Association. Papers and Proceedings.

[16] D. Marin and Th. Verdier. 2003b. Globalization and the Empowerment of Talent. CEPR Discussion Paper No. 4129. London.

[17] J. McLaren. 2000. Globalization and Vertical Structure. American Economic Review. 90. pp. 1239-1254.

[18] S. A. Mohrman, J. R. Galbraith, and E.E. Alwair. 1998. Tomorrow's Organization. San Francisco: Jossey-Bass.

[19] M. Raith. 2003. Competition, Risk, and Managerial Incentives. American Economic Review 93: 4, pp 1425 - 1436.

[20] R.G. Rajan, J. Wulf. 2003. The Flattening Firm: Evidence from Panel Data on the Changing Nature of Corporate Hierarchies, University of Chicago. mimeo.

[21] R.K. Sah and J.E. Stiglitz 1986. The Architecture of Economic Systems: Hierarchies and Polyarchies. American Economic Review. 76:4, pp. 716-27.

[22] K. Schmidt. 1997. Managerial Incentives and Product Market Competition. Review of Economic Studies. 64, pp 191- 214.

[23] X. Vives. 2003. Innovation and Competitive Pressure. CEPR Discussion Paper No.4369. London.

[24] M. Weber. 1968. Economy and Society: An Outline of Interpretive Sociology. New York: Bedminster Press.

[25] O.E. Williamson. 1975. Markets and Hierarchies: Analysis and Antitrust Implications. New York: Free Press. 


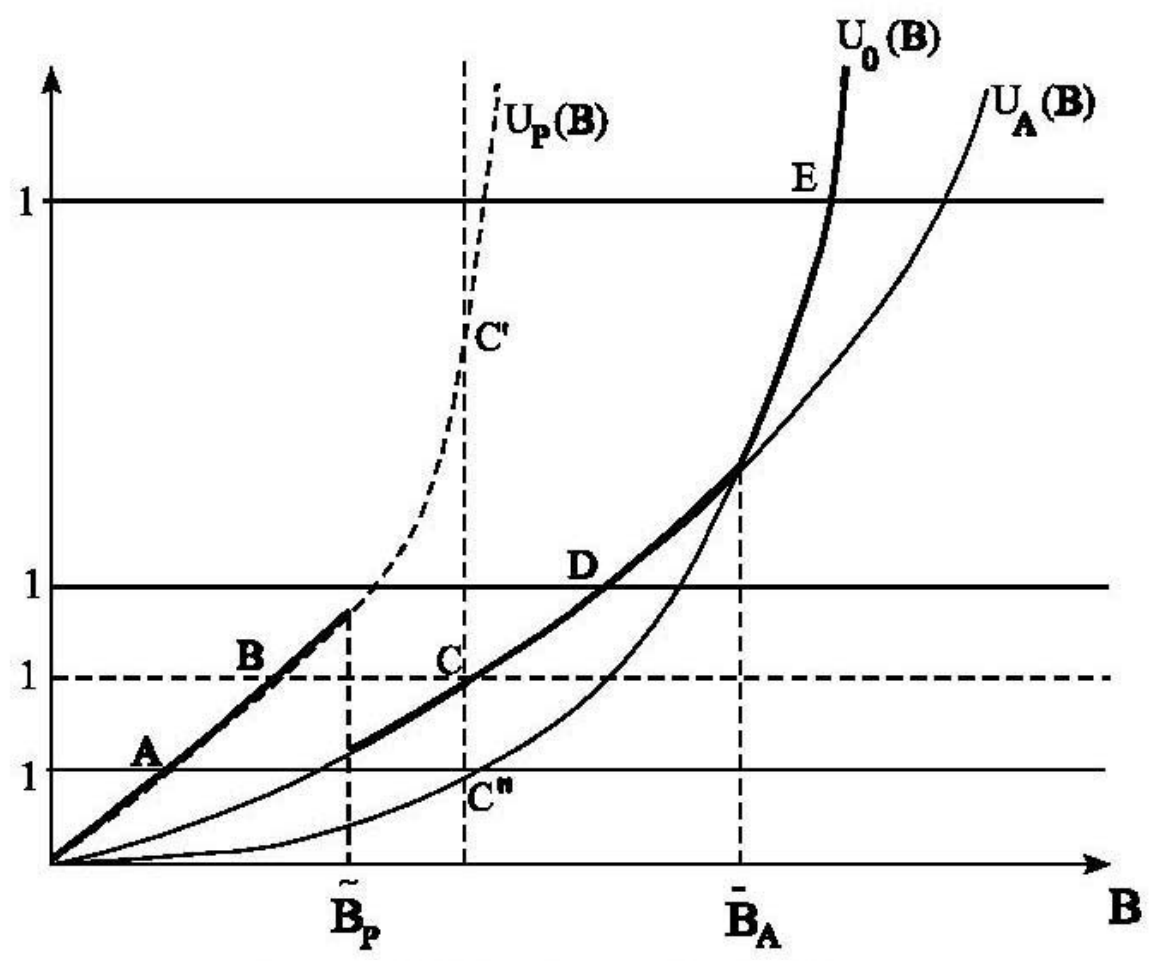

Figure 1: The Firm's Profit Curve

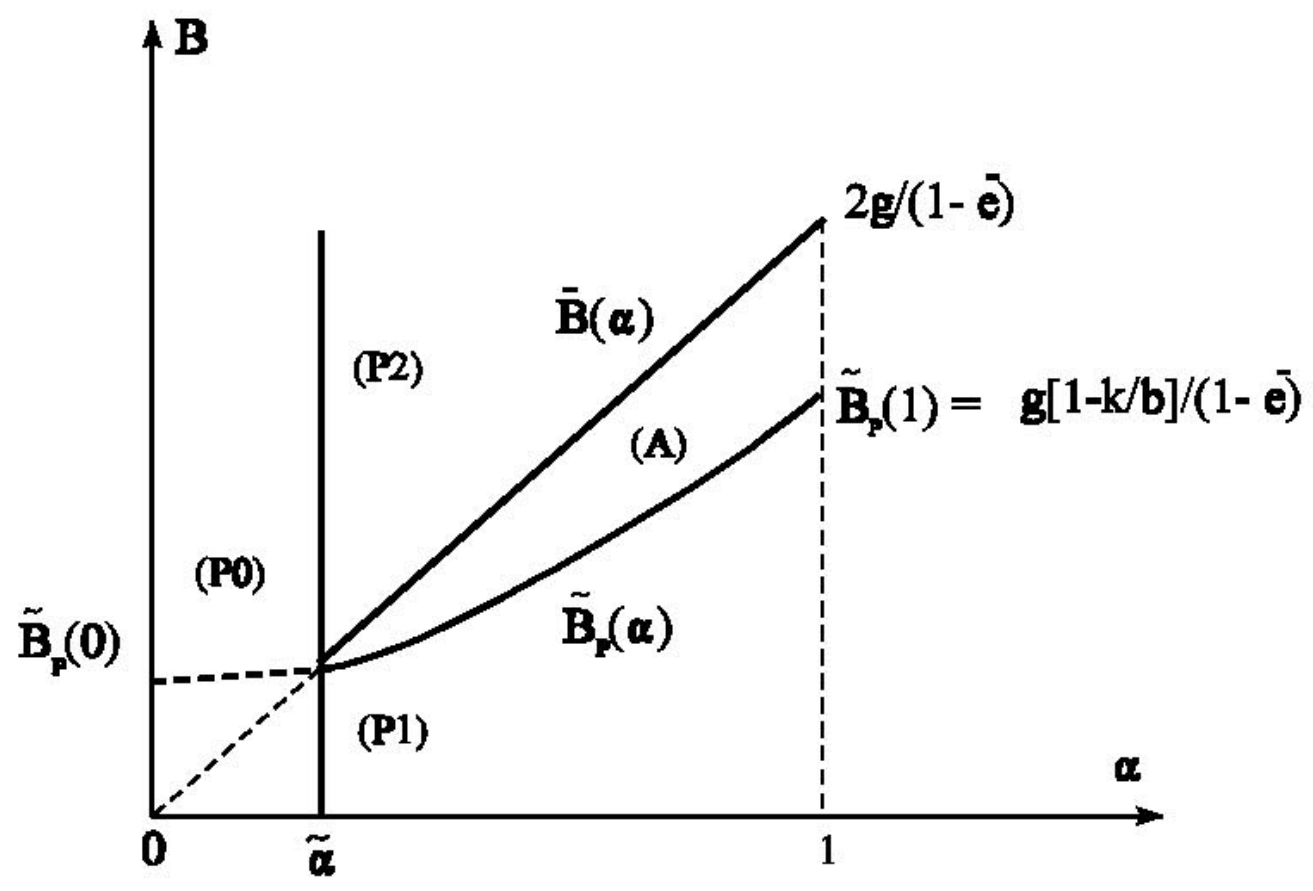

Figure 2: Firm Organization and Market Competition 


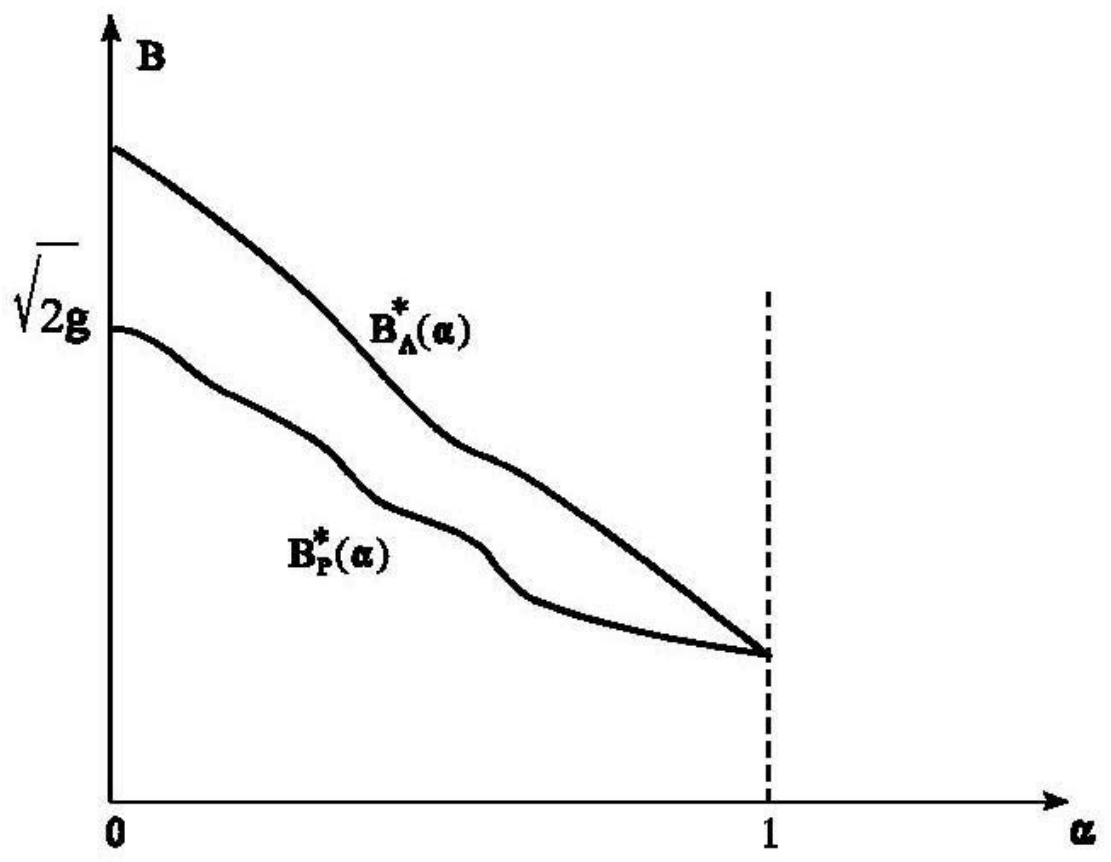

Figure 3: Equilibrium Entry

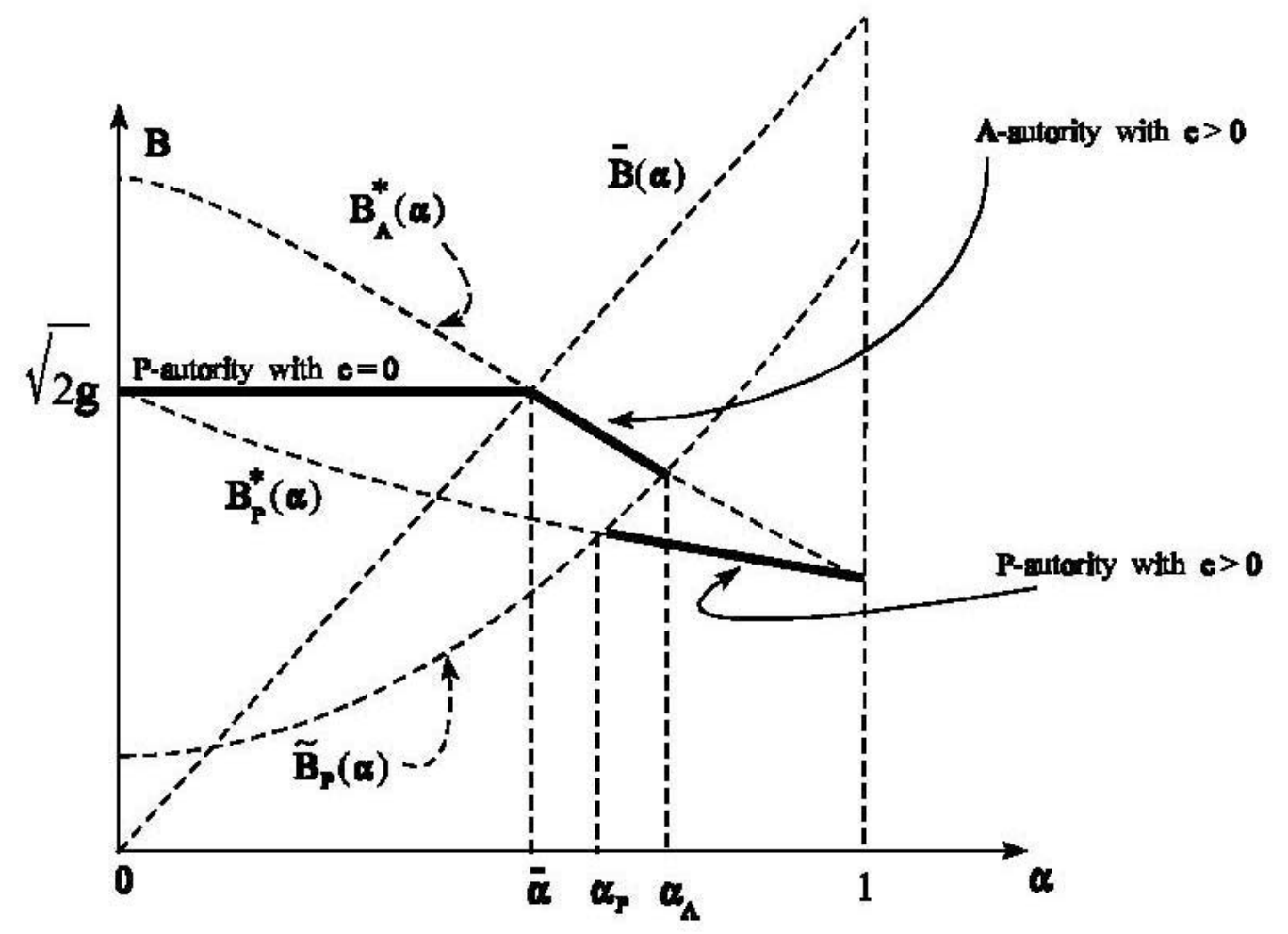

Figure 4: Free Entry Equilibrium Organization 


\section{Appendix I}

\section{Description of the various equilibria in terms of the congruence pa- rameter $\alpha$.}

\section{- Derivation of Figure 2}

Recall the functions:

$$
\begin{gathered}
\widetilde{B}_{P}(\alpha)=\frac{g(1-k / b)}{1-\bar{e} \alpha}, \quad \widetilde{B}_{A}=\frac{g(1-k / b)}{\beta(1-\bar{e})}, \quad \bar{B}(\alpha)=\frac{2 g \alpha}{2-\bar{e}} \\
B_{\min }(\alpha)=\operatorname{Min}\left\{\bar{B}(\alpha) ; \widetilde{B}_{A}\right\}
\end{gathered}
$$

It can be seen that $\widetilde{B}_{P}(\alpha)$ is increasing convex with

$$
\widetilde{B}_{P}(0)=g(1-k / b)>0 \text { and } \widetilde{B}_{P}(1)=\frac{g(1-k / b)}{1-\bar{e}}
$$

We assume for simplicity of exposition:

$$
\text { Condition A.1: } \quad \frac{2(1-\bar{e})}{2-\bar{e}} \beta \bar{e}<(1-k / b)<\frac{2(1-\bar{e})}{2-\bar{e}}
$$

From the first inequality of condition A.1:

$$
\frac{2 \bar{e}}{2-\bar{e}}<\frac{(1-k / b)}{\beta(1-\bar{e})}
$$

Hence $\bar{B}(\alpha)<\bar{B}(1)<\widetilde{B}_{A}$ and $B_{\min }(\alpha)=\operatorname{Min}\left\{\bar{B}(\alpha) ; \widetilde{B}_{A}\right\}=\bar{B}(\alpha)$

¿From the second inequality of condition A.1:

$$
\widetilde{B}_{P}(1)=\frac{(1-k / b) g}{1-\bar{e}}<\frac{2 g}{2-\bar{e}}=\bar{B}(1)
$$

Hence the two curves $\bar{B}(\alpha)$ and $\widetilde{B}_{P}(\alpha)$ look like in figure 2 and do intersect with each other at some point $\widetilde{\alpha}$. 


\section{- Derivation of Figure 3}

Now consider the "equilibrium" levels of profits $B_{P}^{*}(\alpha)$ under a P-organization (with high effort $e$ ) and $B_{A}^{*}(\alpha)$ under the A-organization. They are, respectively given by :

$$
\frac{B_{P}^{2}(1-\bar{e} \alpha)^{2}}{2 g}+\bar{e} \alpha B_{P}-1=0
$$

and

$$
\frac{B_{A}^{2}(1-\bar{e})^{2}}{2 g}+\bar{e} \alpha B_{A}-1=0
$$

Differentiation gives immediately:

$$
\begin{gathered}
\frac{\partial B_{P}^{*}(\alpha)}{\partial \alpha}=\frac{-\bar{e} B_{P}\left[1-\frac{B_{P}(1-\bar{e} \alpha)}{g}\right]}{\frac{B_{P}(1-\bar{e} \alpha)^{2}}{g}+\bar{e} \alpha}<0 \\
\frac{\partial B_{A}^{*}(\alpha)}{\partial \alpha}=\frac{-\bar{e} B_{A}}{\frac{B_{A}(1-\bar{e})^{2}}{g}+\bar{e} \alpha}<0
\end{gathered}
$$

The two functions are decreasing in $\alpha$. Moreover, from (6.2) and (6.3)

$$
\begin{gathered}
B_{P}^{*}(\alpha)<B_{A}^{*}(\alpha) \text { for all } \alpha \in\left[0,1\left[\text {, and } B_{P}^{*}(1)=B_{A}^{*}(1)=B^{*}\right.\right. \\
\text { with } B^{*} \text { such that } \frac{\left(B^{*}\right)^{2}(1-\bar{e})^{2}}{2 g}+\bar{e} B^{*}=1
\end{gathered}
$$

Also $B_{P}^{*}(0)=\sqrt{2 g}$ which is the equilibrium firm's profits under a P-organization with no agent's effort $(e=0)$. The two functions $B_{P}^{*}(\alpha)<B_{A}^{*}(\alpha)$ are then as represented in figure 3 .

The largest possible equilibrium profit value is $B_{A}^{*}(0)=(\sqrt{2 g}) /(1-\bar{e})$. Thus to ensure that the principal's effort levels $E$, are always less than 1 (to be probabilities), we need

$$
B(1-\alpha \bar{e})<g \quad \text { for all possible values of } B \text { and } \alpha \in[0,1]
$$

A sufficient condition for this to hold is

$$
B_{A}^{*}(0)<g
$$


or the following condition

$$
\text { Condition A.2: } \quad \frac{2}{(1-\bar{e})^{2}}<g
$$

which we assume to be satisfied ( the cost function $g(E)$ is convex enough)

\section{- Derivation of Figure 4}

A number of useful results are described now:

Lemma 6.1. Given condition A:2, we have

$$
B_{P}^{*}(1)=B_{A}^{*}(1)=B^{*}<\bar{B}(1)=\frac{2 g}{2-\bar{e}}
$$

Proof. Indeed $B^{*}<\bar{B}(1)$ if and only if

$$
\frac{\left(B^{*}\right)^{2}(1-\bar{e})^{2}}{2 g}+\bar{e} B^{*}=1<\frac{(\bar{B}(1))^{2}(1-\bar{e})^{2}}{2 g}+\bar{e} \bar{B}(1)
$$

the last inequality is equivalent to

$$
1<2 g\left[\frac{(1-\bar{e})^{2}}{(2-\bar{e})^{2}}+\frac{\bar{e}}{2-\bar{e}}\right]
$$

which is satisfied when

$$
1<2 g \frac{(1-\bar{e})^{2}}{(2-\bar{e})^{2}}
$$

which is implied by condition A.2.

Lemma 6.2. There exists a unique value $\alpha=\bar{\alpha}$ between 0 and 1 such that

$$
B_{A}^{*}(\bar{\alpha})=\bar{B}(\bar{\alpha})=B_{P}^{*}(0)=\sqrt{2 g}
$$

In other words, $\bar{\alpha}$ is at the common intersection of the curves $B_{A}^{*}(\alpha), \bar{B}(\alpha)$ and the horizontal line $B=B_{P}^{*}(0)=\sqrt{2 g}$ 
Proof. Consider the value $\bar{\alpha} \in] 0,1[$ such that :

$$
B_{P}^{*}(0)=\sqrt{2 g}=B_{A}^{*}(\bar{\alpha})
$$

Such a value exists, as $B_{A}^{*}(\alpha)$ is strictly decreasing in $\alpha$ and $B_{A}^{*}(0)>B_{P}^{*}(0)>$ $B_{P}^{*}(1)=B_{A}^{*}(1)=B^{*}$. From (6.4), it follows that

$$
\frac{\left(B_{A}^{*}(\bar{\alpha})\right)^{2}}{2 g}=1
$$

and by definition of $B_{A}^{*}(\alpha)$,

$$
\frac{\left(B_{A}^{*}(\bar{\alpha})\right)^{2}(1-\bar{e})^{2}}{2 g}+\overline{e \alpha}\left(B_{A}^{*}(\bar{\alpha})\right)=1
$$

at the same time $\bar{B}(\alpha)$ is defined by the value of profits such that

$$
\frac{\bar{B}(\alpha)^{2}(1-\bar{e})^{2}}{2 g}+\bar{e} \alpha \bar{B}(\alpha)-1=\frac{\bar{B}(\alpha)^{2}}{2 g}-1
$$

(indifference between an A-organization and a DS-organization with $e=0$ ). Clearly

$$
\frac{\left(B_{A}^{*}(\bar{\alpha})\right)^{2}(1-\bar{e})^{2}}{2 g}+\overline{e \alpha}\left(B_{A}^{*}(\bar{\alpha})\right)-1=\frac{\left(B_{A}^{*}(\bar{\alpha})\right)^{2}}{2 g}-1=0
$$

Hence $B_{A}^{*}(\bar{\alpha})=\bar{B}(\bar{\alpha})$ and $\bar{\alpha}$ is at the common intersection of the curves $B_{A}^{*}(\alpha)$, $\bar{B}(\alpha)$ and the horizontal line $B=B_{P}^{*}(0)=\sqrt{2 g}$.

Configuration of parameters ensuring the existence of an A-equilibrium.

Clearly there will be an A-organizational equilibrium if and only if there exists $\alpha$ such that

$$
\widetilde{B}_{P}(\alpha)<B_{A}^{*}(\alpha)<\bar{B}(\alpha)
$$

Given that $B_{A}^{*}(\alpha)$ is decreasing in $\alpha$ and that $\bar{B}(\alpha)$ is increasing in $\alpha$, this condition is equivalent to the existence of some $\alpha>\bar{\alpha}$ such that $\widetilde{B}_{P}(\alpha)<B_{A}^{*}(\alpha)$. It is easy to see that, because of the continuity of the various functions in $\alpha$, this is equivalent to $\widetilde{B}_{P}(\bar{\alpha})<B_{A}^{*}(\bar{\alpha})$. Now $\bar{\alpha}$ is determined by

$$
\sqrt{2 g}=\bar{B}(\bar{\alpha})=\frac{2 g \bar{\alpha}}{2-\bar{e}}
$$


Hence

$$
\bar{\alpha}=\frac{2-\bar{e}}{\sqrt{2 g}}
$$

After substitution, the condition $\widetilde{B}_{P}(\bar{\alpha})<B_{A}^{*}(\bar{\alpha})$ writes as:

$$
\text { Condition A.3 } g\left(1-\frac{k}{b}\right)<\sqrt{2 g}-\bar{e}(2-\bar{e})
$$

which we assume to be satisfied. ( If this is not the case, the A-organization cannot be an equilibrium outcome with free entry).

The whole picture of the structure of the organizational equilibria in terms of $\alpha$ is then described by the following proposition

Proposition 6.3. There exist $\alpha_{P}$ and $\alpha_{A}$ in $[0,1]$ with $0<\bar{\alpha}<\alpha_{A}$ and $\alpha_{P} \leq$ $\alpha_{A} \leq 1$ such that

i) the $D S$-organization with $e=0$ is an equilibrium for $\alpha \in\left[0, \operatorname{Min}\left(\bar{\alpha}, \alpha_{P}\right)[\right.$.

ii) the P-organization with $e=\bar{e}$ is an equilibrium for $\alpha \in\left[\alpha_{P}, 1[\right.$

iii) the A-organization is an equilibrium for $\alpha \in\left[\bar{\alpha}, \alpha_{A}\right]$

iv) at $\alpha=1$, the firm organization is irrelevant.

Proof. 1) Assume first that $B^{*}<\widetilde{B}_{P}(1) . B_{P}^{*}(\alpha)$ and $B_{A}^{*}(\alpha)$ are decreasing continuous functions of $\alpha$ and that $\widetilde{B}_{P}(\alpha)$ is increasing continuous in $\alpha$. Also with condition A.3, $B_{A}^{*}(0)>B_{P}^{*}(0)=\sqrt{2 g}>g\left(1-\frac{k}{b}\right)=\widetilde{B}_{P}(0)$ and $B_{A}^{*}(1)=B_{P}^{*}(1)=$ $B^{*}<\widetilde{B}_{P}(1)$. Hence there exists by continuity $\alpha_{P}$ and $\alpha_{A}$ in $[0,1]$ such that $B_{P}^{*}\left(\alpha_{P}\right)=\widetilde{B}_{P}\left(\alpha_{P}\right)$ and $B_{A}^{*}\left(\alpha_{A}\right)=\widetilde{B}_{P}\left(\alpha_{A}\right)$. Because of condition A.3, $B_{A}^{*}(\bar{\alpha})>$ $\widetilde{B}_{P}(\bar{\alpha})$. Therefore $B_{A}^{*}(\bar{\alpha})-\widetilde{B}_{P}(\bar{\alpha})>0=B_{A}^{*}\left(\alpha_{A}\right)-\widetilde{B}_{P}\left(\alpha_{A}\right)$. As $B_{A}^{*}(\alpha)-\widetilde{B}_{P}(\alpha)$ is decreasing in $\alpha$, it follows clearly that $\bar{\alpha}<\alpha_{A}$. Also, as $B_{A}^{*}(\alpha)>B_{P}^{*}(\alpha)$ for all $\alpha \in\left[0,1\left[, B_{A}^{*}(\alpha)-\widetilde{B}_{P}(\alpha)>B_{P}^{*}(\alpha)-\widetilde{B}_{P}(\alpha)\right.\right.$ for all $\alpha \in[0,1[$. Hence $B_{A}^{*}\left(\alpha_{A}\right)-\widetilde{B}_{P}\left(\alpha_{A}\right)=0=B_{P}^{*}\left(\alpha_{P}\right)-\widetilde{B}_{P}\left(\alpha_{P}\right)<B_{A}^{*}\left(\alpha_{P}\right)-\widetilde{B}_{P}\left(\alpha_{P 2}\right)$. As again $B_{A}^{*}(\alpha)-\widetilde{B}_{P}(\alpha)$ is decreasing in $\alpha$, we get $\alpha_{P}<\alpha_{A}$.

2) Assume that $B^{*}>\widetilde{B}_{P}(1)$. Then, for all $\alpha$ in $0,1\left[B_{A}^{*}(\alpha)>B_{P}^{*}(\alpha)>B_{P}^{*}(1)=\right.$ $B^{*}>\widetilde{B}_{P}(1)>\widetilde{B}_{P}(\alpha)$. In that case we pose $\alpha_{P}=\alpha_{A}=1$.

With these definitions of $\alpha_{P}$ and $\alpha_{A}$, it is then easy to verify the conditions which provide i),ii) ,iii) and iv).

i) The domain of validity for a DS-organization with $e=0$ to be an equilibrium is $\sqrt{2 g}>B_{\min }(\alpha)$ and the fact the P-organization with $e=\bar{e}$ is not possible with 
free entry. Given condition A.1, the first aspect can be restated as $\sqrt{2 g}>\bar{B}(\alpha)$ which is equivalent to $\alpha<\bar{\alpha}$. When $\bar{\alpha}<\alpha_{P}$ then this condition is also sufficient. When $\alpha_{P}<\bar{\alpha}$ however, this is not sufficient because in such a case, there exists a $\alpha \in] \alpha_{P}, \bar{\alpha}\left[\right.$ such that $B_{P}^{*}(\alpha)<\widetilde{B}_{P}(\alpha)$. For such an $\alpha$, a P-organization with $e=\bar{e}$ is possible with free entry. This organization will always dominate a DSorganization with $e=0$. Hence the condition for a DS-organization with $e=0$ to be an equilibrium becomes in such a case $\alpha<\alpha_{P}$. Summarizing the two previous cases, we can say that a DS-organization with $e=0$ is an equilibrium for $\alpha \in\left[0, \operatorname{Min}\left(\bar{\alpha}, \alpha_{P}\right)[\right.$.

ii) The domain of validity for a P-organization with $e=\bar{e}$ to be an equilibrium simply $B_{P}^{*}(\alpha)<\widetilde{B}_{P}(\alpha)$. Given the definition of $\alpha_{P}$, this is equivalent to $\alpha \in\left[\alpha_{P}, 1[\right.$

iii) Similarly the domain of validity for an A-organization to be an equilibrium is $\widetilde{B}_{P}(\alpha)<B_{A}^{*}(\alpha)<B_{\min }(\alpha)=\bar{B}(\alpha)$ which is equivalent to $\alpha \in\left[\bar{\alpha}, \alpha_{A}\right]$ by the definition of $\bar{\alpha}$ and $\alpha_{A}$.

iv) is trivial as for $\alpha=1$, the two organizations are equivalent

The characterization is represented in figure 4 for the case $\bar{\alpha}<\alpha_{P}$. Notice that for $\alpha \in\left[\alpha_{P}, \alpha_{A}\right.$ [ there are multiple organizational equilibria: the P-organization with high effort and the A-organization. 